Canadian Journal of Fisheries and Aquatic Sciences

Canadian

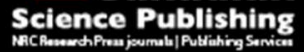

Journal canadien des sciences halieutiques et aquatiques

\title{
Trends in body condition of smallmouth bass and northern pike (1982-2013) following multiple ecological perturbations in the St. Lawrence River
}

\begin{tabular}{|r|l|}
\hline Journal: & Canadian Journal of Fisheries and Aquatic Sciences \\
\hline Manuscript ID & cjfas-2016-0160.R3 \\
\hline Manuscript Type: & Article \\
\hline Date Submitted by the Author: & 22-Nov-2016 \\
\hline Complete List of Authors: & $\begin{array}{l}\text { Crane, Derek P.; Coastal Carolina University, } \\
\text { Farrell, John M.; State University of New York }\end{array}$ \\
\hline Keyword: & $\begin{array}{l}\text { INVASIVE SPECIES < Organisms, body condition, St. Lawrence River, } \\
\text { round goby, dreissenid mussles }\end{array}$ \\
\hline \multicolumn{2}{|l}{} \\
\hline
\end{tabular}

SCHOLARONE ${ }^{m}$

Manuscripts 
1 Trends in body condition of smallmouth bass and northern pike (1982-2013) following multiple

2 ecological perturbations in the St. Lawrence River

3 Derek P. Crane ${ }^{\mathrm{a}, *}$ and John M. Farrell ${ }^{\mathrm{b}}$

4

$5 \quad{ }^{a}$ Coastal Carolina University; 107 Chanticleer Drive East, Conway, SC 29526, USA

$6 \quad$ (843) 349-4065

7 dcrane@coastal.edu

8

9

10

${ }^{\mathrm{b}}$ State University of New York - College of Environmental Science and Forestry; 250 Illick

Hall, 1 Forestry Drive, Syracuse, New York 13210, USA

(315) 470-6990

jmfarrell@esf.edu

14

15

*corresponding author

16

17

18

19

20

21

22

23

24

25

26

27

28

29

30

31

32

33

34 
Abstract

Body condition indices can be used to investigate fish response to biological or

37 environmental change. We used quantile regression to analyze a 32-year weight-length dataset (1982-2013) for smallmouth bass (Micropterus dolomieu) and northern pike (Esox lucius) from the St. Lawrence River to examine changes in condition (weight-at-length) during three ecologically distinct time periods. Condition of both species varied among time periods, with smallmouth bass experiencing greater proportional changes than northern pike. Smallmouth bass

42 weight-at-length was greatest during 2005-2013 and lowest during 1982-1992. Northern pike 43 weight-at-length was greatest during 2005-2013 for quantiles $\geq 0.5$, similar between the $1982-$ 441992 and 2005-2013 time periods for lower quantiles, and lowest during 1993-2004. The most likely weight-length model for smallmouth bass included terms for length, presence of round goby (Neogobius melanostomus), presence of dreissenid mussels, and an interaction between

47 length and dreissenid mussels $\left(w_{i}=0.93\right)$. The most likely model for northern pike included 48 terms for length, presence of round goby, presence of dreissenid mussels, water temperature, 49 conspecific abundance, and sex $\left(w_{i}=0.56\right)$. Invasive species and environmental change related 50 to invasive species have altered the condition of smallmouth bass and northern pike in the St. 51 Lawrence River. 


\section{Introduction}

Changes in aquatic food web structure and function and environmental conditions can affect the availability and composition of prey, physiological function, and subsequently, body condition of fishes (Johnson et al. 2005; Rennie et al. 2009; Crane et al. 2015). Body condition of fishes is commonly determined with a variety of indices (e.g., Fulton's K, relative condition factor, relative weight, mean or quantile weight-length relationships; Pope and Kruse 2007, Cade et al. 2008) that assume heavier fish are in a better nutritional state than lighter fish of the same length. Recruitment potential (Ratz and Lloret 2003; Marshall and Frank 1999), growth (Willis 1989; VanDeValk et al. 2008), and mortality (Dutil and Lambert 2000; Johnson 2008) have been related to body condition indices. Indices of body condition based on weight-length relationships are frequently incorporated in fisheries assessments because they are a relatively reliable measure of energy reserves, collection of weight and length data are often standard parts of fisheries surveys, and data collection is non-invasive and relatively inexpensive (Blackwell et al. 2000; Pope and Kruse 2007). Body condition analyses can be used to assess availability of prey to commercial and sport fishes (Marwitz and Hubert 1997; Porath and Peters 1997) and investigate fish response to biological or environmental change in aquatic ecosystems (Rennie et al. 2009, Staton et al. 2014; Crane et al. 2015). Rennie et al. (2009) emphasized the importance of using long term data sets with multiple explanatory variables to better understand the effects of biological and environmental change on fish condition, yet analyses considering effects of multiple biotic and abiotic factors on body condition are relatively rare.

The availability of long-term weight-length data for predatory fishes such as smallmouth bass (Micropterus dolomieu) and northern pike (Esox lucius) and major ecological changes that have occurred over the past several decades make the St. Lawrence River an excellent model 
81 ecosystem for investigating how biological and environmental factors affect the body condition

82 of predatory fishes. Smallmouth bass and northern pike are the most abundant predatory fishes

83 and most important sport fishes in the Thousand Islands region of the St. Lawrence River

84 (McCullough and Gordon 2014). Smallmouth bass and northern pike also have different feeding

85 strategies, habitat use, and thermal preferences. The smallmouth bass is a warmwater, generalist

86 predator that typically occupies rocky habitats and feeds on benthic prey, whereas, the northern

87 pike is a coolwater species that occupies vegetated littoral zones and typically feeds on fishes

88 higher in the water column. Therefore, body condition of smallmouth bass and northern pike

89 may respond differently to changes in biological and environmental conditions of the ecosystems

they inhabit. Body condition can also vary between sexes within a species (Doyon et al. 1988);

91 thus, the response in body condition to ecological change may also vary between sexes. For

92 example, male smallmouth bass in Lake Erie experienced increased energetic costs of nest

93 guarding following invasion by round goby (Steinhart et al. 2005) because the round goby is an

94 aggressive nest predator that male smallmouth bass must defend against. Female smallmouth

95 bass do not nest guard and therefore are not subject to increased energetic costs associated with

96 defending a nest against round gobies. The objectives of this study were to (1) document long-

97 term trends in smallmouth bass and northern pike body condition across a range of quantiles, (2)

98 identify any differences in body condition between male and female fish and determine if male

99 and female fish responded differently to biological and environmental change, and (3) identify

100 important ecological and environmental factors that affect body condition of smallmouth bass

101 and northern pike across a range of body condition quantiles and make comparisons between the

102 two species. We used quantile regression to analyze 32 years of weight-length data for northern 
103 pike and smallmouth bass from the Thousand Islands region of the St. Lawrence River to address 104 these objectives.

\section{Materials and methods}

\section{Study location and fish collection}

The St. Lawrence River is part of the Great Lakes ecosystem, which has experienced substantial ecological change due to complex, interacting top-down and bottom-up drivers over the past several decades (Mills et al. 2003; Farrell et al. 2010; Murry and Farrell 2014). Some of the most rapid and dramatic ecological changes have been associated with invasion and

111 proliferation of dreissenid mussels in the early 1990's and the round goby (Neogobius

112 melanostomus) in the mid 2000's (Farrell et al. 2010). Dreissenid mussels sequestered nutrients

113 in the benthos, which resulted in increased water transparency and decreased pelagic

114 productivity (i.e., decreased food for many fishes; Mills et al. 2003). The round goby, a benthic-

115 oriented consumer of dreissenid mussels, rapidly populated the upper St. Lawrence River in

1162005 and became an important food resource for many predators; thus, creating a link between

117 dreissenid mussels and higher trophic levels (Farrell et al. 2010). Coinciding with the invasions

118 of dressenid mussles and round goby, the double-crested cormorant population (Phalacrocorax 119 auritus) expanded in the St. Lawrence River region. Double-crested cormorants prey heavily on 120 a variety of fishes. From 1999 through 2013 double-crested cormorants from three islands in the 121 St. Lawrence River consumed an estimated 145 million fish (Johnson et al. 2015). Competition 122 between double-crested cormorants and piscivorous fishes for food may directly and indirectly 123 affect body condition of fishes in competition with double-crested cormorant. Smallmouth bass and northern pike were sampled from the Thousands Islands region of

125 the St. Lawrence River from 1982-2013 as part of the New York State Department of 
126 Environmental Conservation's annual fish stock assessment (McCullough and Gordon 2014).

127 Sampling was conducted annually in the St. Lawrence River from Clayton, New York, USA

128 downstream to Morristown, New York, USA and occurred from late July through early August

129 (Fig. 1). Fishes were sampled with multifilament gillnets from 1982 through 2003 and

130 monofilament gill nets from 2004 through 2013. Paired sampling indicated that catchability of

131 smallmouth bass and northern pike did not appreciably differ between the two net types

132 (McCullough and Gordon 2014). Nets were $61 \mathrm{~m}$ long and $8 \mathrm{~m}$ deep. Each net contained eight

133 panels with stretch mesh ranging in size from $38-152 \mathrm{~mm}$. Thirty-two net sets were fished

134 overnight at fixed sites each year. Sample locations were in 3-20 m of water, and all nets were

135 fished on the bottom. Total length $(\mathrm{mm})$ and weight $(\mathrm{g})$ were recorded for collected fish. To

136 eliminate potential biases by including small fish that were not well represented in the samples,

137 we only included smallmouth bass $\geq 200 \mathrm{~mm}$ and northern pike $\geq 475 \mathrm{~mm}$ in weight-length

138 analyses.

139

140

\section{Body condition analyses}

We used two quantile regression analyses, based on weight-length data for 4499

142 smallmouth bass and 2623 northern pike, to investigate the response in body condition of

143 smallmouth bass and northern pike to ecological change in the St. Lawrence River (Table 1).

144 First, we analyzed weight-length relationships for smallmouth bass and northern pike to

145 determine if body condition changed during three time periods in 1982-2013 and if weight-

146 length relationships differed between sexes. Next, we investigated the effects of several

147 biological and environmental factors on weight-length relationships for northern pike and

148 smallmouth bass to identify the most important drivers of change in body condition during the 
149 three specified time periods. Models for the 0.1-0.9 quantiles (in increments of 0.1 ) were fitted 150 using the 'quantreg' package (rq () function) in R (Koenker 2016). Model parameters were 151 estimated using the "br" method and 95\% confidence intervals were estimated using the "rank" 152 method (Koenker 2016).

We used Bayesian information criterion (BIC; Schwarz 1978), information loss ( $\triangle \mathrm{BIC}$;

154 Raftery 1995), and Schwarz weights ( $w_{\mathrm{i}}$; Wagenmakers and Farrell 2004; Link and Barker, 155 2006) to evaluate and select the most likely model structure for each analysis (i.e., variables to 156 include in the model) based on the 0.5 quantile. Bayesian information criterion allows for 157 comparison of the likelihood individual models in a series of models fitted on common data. We 158 chose to use BIC over Akaike information criteria (AIC) for model selection because our 159 samples sizes for smallmouth bass and northern pike were large (i.e., $\mathrm{n}>>$ parameter numbers 160 creating the true model) and when samples size are large, AIC may lead to selection of an 161 overparameterized model that includes variables with limited biological importance or effect 162 sizes. The use of BIC provided a conservative model selection approach that satisfied our 163 objective of identifying the most important drivers of change in body condition of smallmouth 164 bass and northern pike in the St. Lawrence River. Increasing likeliness of a model corresponds 165 to lower BIC values (Raftery 1995; Murtaugh 2014). Information loss is the difference in BIC 166 between a given model and the model with the lowest BIC value. Schwarz weight is the 167 comparative probability that a given model is the most likely model within the set of models 168 analyzed (Link and Barker 2006). 
To investigate trends in body condition of smallmouth bass and northern pike during

1721982 through 2013, we examined weight-length relationships during three ecologically different

173 time periods. The first time period (1982-1992) was defined as the base time period, prior to

174 significant invasive species introductions. We used 1992 as the upper end point for this time

175 period because dreissenid mussels were first detected in the study area in 1991 but were not

176 prolific until 1993 (Rodger Klindt, New York State Department of Environmental Conservation

177 - Region 6, 317 Washington St \# 7, Watertown, NY 1360, personal communication) The second

178 time period (1993-2004) was characterized by expansion and growth of dreissenid mussel and

179 double-crested cormorant populations in the upper St. Lawrence River (Fig. 2), and decreased

180 abundance of smallmouth bass and northern pike (Fig. 2). The third time period (2005-2013)

181 was defined by invasion of round goby (Farrell et al. 2010), increased abundance of smallmouth

182 bass, decreased abundance of northern pike, and a large but variable population of double-

183 crested cormorant.

Eight competing weight-length models were fitted for the 0.5 quantile to determine the most likely model structure (Table 2). The most likely model structure for the 0.5 quantile was then applied to models for the $0.1-0.9$ quantiles to investigate the effects of time period, sex, and one-way interactions between length, sex, and time period on body condition of smallmouth bass 188 and northern pike. Applying the underlying model for the 0.5 quantile to additional quantiles is 189 reasonable because parameters that are uninformative in additional quantiles would have 190 estimates near zero. The standard weight-length relationship for fish is described by the 191 equation: 
194

195

196

197

198

199

200

201

202

203

204

205

206

207

208

209

210

211

212

213

214

215

216

(1) $\quad W=\beta_{0} T L^{\beta 1}$

where $W=$ weight $(\mathrm{g}), T L=$ total length $(\mathrm{mm}), \beta_{0}=$ intercept, and $\beta_{1}=$ allometric growth parameter (Keys, 1928). Weight-length models were log-transformed and adapted to include time period and sex as categorical variables. A variable for sex $(0=$ male, $1=$ female $)$ was included to determine if body condition differed between sexes and if changes in body condition during the time periods examined differed between sexes. Models were $\log _{10}$-transformed prior to being fitted because linear quantile regression methods are better developed than nonlinear methods (Cade et al. 2008, 2011).

Following model selection, the most likely $\log _{10}$-transformed models for each species were back-transformed to estimate percent changes in weight-at-length between time periods and estimate time period and species specific weight-at-length lengths for quantiles $0.1-0.9$.

Differences in parameter estimates between time periods were calculated using the 'contr.treatment' option when fitting models in R. Unlike back-transformed parameter estimates for mean weight-length relationships, back-transformed parameter estimates for quantile weightlength relationships are unbiased and can be used to provide valid estimates of weight-at-length (Cade et al. 2008). Because an important interaction was identified between time period and length in the smallmouth bass model, multiplicative changes in weight-at-length for smallmouth bass needed to be estimated at specific lengths. Multiplicative changes in weight for smallmouth bass were estimated by back-transforming models and rescaling the intercepts (time period variable) to the desired length of interest. This was accomplished by estimating parameters for models where the total lengths were divided by the length of interest. In rescaled models the 
217 base 10 exponentiated differences in intercept values (and 95\% confidence intervals) between 218 time periods were equal to the multiplicative change in weight for the target length class. We 219 chose to use the median values of lengths for stock, quality, preferred, and memorable size class 220 smallmouth from Gabelhouse's (1984) five-cell model to examine changes in smallmouth bass 221 weight-at-length. Interactive effects of time period and length or time period and sex were not 222 identified as important predictors in the northern pike model; therefore, multiplicative changes in 223 weight-at-length (and 95\% confidence intervals) were not size or sex specific and were estimated 224 by base 10 exponentiating the differences between parameter estimates and the upper and lower 225 bounds of $95 \%$ confidence intervals for the time period parameters in the model. For example, 226 the difference in time period parameter estimates between time periods 1 and 2 in the northern 227 pike model ( 0.5 quantile) was -0.0119 . When base 10 exponentiated, this equated to a 228 multiplicative change in weight of 0.972 (i.e., $2.8 \%$ decrease in weight) between time periods 1 229 and 2. To visually examine changes in weight-at-length between time periods and across 230 quantiles $0.1-0.9$, we plotted multiplicative changes in weight-at-length and $95 \%$ confidence 231 intervals for changes that occurred from time period 1 to time period 2, time period 1 to time 232 period 3, and time period 2 to time period 3. We also plotted time-specific weight-at-length 233 across quantiles $0.1-0.9$ for selected length classes of smallmouth bass and northern pike. The 234 BIC analysis indicated that weight-at-length was dependent on sex for northern pike but not 235 smallmouth bass; therefore, plots of weight-at-length are sex-specific for northern pike but not 236 smallmouth bass. The size distribution of male northern pike was more restricted than the size 237 distribution of female northern pike, so we estimated weight-at-length for fewer length classes of 238 male northern pike. 


\section{Biological and environmental effects}

To investigate the effects of biological and environmental change on body condition of smallmouth bass and northern pike we fitted a series of weight-length models for quantiles $0.1-$ 0.9 (Table 3), including terms for the presence of dreissenid mussels, presence of round goby, mean summer water temperature (Fig. 2), catch per unit effort (CPU) of conspecifics (Fig. 2), and abundance of double-crested cormorants (Fig. 2). In the time period analysis, indicator variables encompassed all factors affecting weight-length relationships during each specific time period. Replacing time period variables with variables for biological and environmental factors allowed us to partition the effects observed between time periods across the environmental and biological variables examined. Based on results from the time period analysis, sex specific models were fitted for northern pike but not smallmouth bass. Median weight-length models, based on the standard weight-length equation (eq. 1), were log-transformed and adapted to include variables for biological and environmental factors and their one-way interactions. Indicator variables were used to account for the presence round goby and dressinid mussels. Annual CPU data for northern pike and smallmouth bass were based on the NYSDEC's annual summer stock assessment for the Thousand Islands region of the St. Lawrence River (described above). Annual abundance data for double-crested cormorants in the Thousand Islands region were based on nest count surveys conducted by the NYSDEC. Variance inflation factors (VIF) were calculated for all environmental and biological variables, using the vif() function in the 'car' package for R (Fox and Weisberg, 2016), to identify and remove highly correlated variables because collinearity can affect estimation and interpretation of model coefficients. Variables with highest VIF were sequentially dropped until VIF was $<5.0$ for all predictors. Zurr et al. (2010) suggested that multicollinearity may be an issue when VIF is as low as 2 if effect sizes 
263 are small. However, O’Brien (2007) demonstrated that substantially higher VIF values may be

264 acceptable because multicollinearity is not the only factor affecting variation of parameter

265 estimates (e.g., increasingly larger sample sizes decrease variation of parameter estimates).

266 Northern pike CPU had the greatest VIF that was $<5.0($ VIF $=4.77)$ in our study and we found

267 confidence intervals around the parameter estimate for this variable to be acceptable (Fig. 3).

268 The variable for double-crested cormorant abundance had high VIF values for the smallmouth 269 bass $(\mathrm{VIF}=10.24)$ and northern pike $(\mathrm{VIF}=7.28)$ models, and was therefore not included in 270 analyses for both species.

271 Ambient water temperature is a major determinant of fish bioenergetics and may affect

272 fish weight-length relationships. Mean annual summer water temperatures for 1982-2002 were

273 based on St. Lawrence River daily water temperature data collected at the DuPont Canada

274 facility in Maitland, Ontario. May-July was considered the summer growing season for northern

275 pike because sampling commenced in late July. June through July was considered the summer

276 growing season for smallmouth bass because low water temperatures and spawning limit

277 smallmouth bass growth during May. Since water temperature data were not available for 2003-

278 2013, we used the relationship between mean monthly summer water temperature for the St.

279 Lawrence River at Maitland, Ontario and mean monthly air temperature at Watertown

280 International Airport for 1965-2002 (Watertown, New York; data retrieved from the National

281 Climatic Data Center, available at: www.ncdc.noaa.gov/cdo-web/) to predict mean summer

282 water temperatures at Maitland, Ontario for 2003-2013. Mean monthly water temperatures for

283 May-July were predicted for each year (2003-2013) with the equation: 
Predicted mean monthly temperatures were averaged for each year to determine the average growing season temperature for northern pike (May-July) and smallmouth bass (June-July). Observed and predicted water temperatures (1965-2002) were moderately correlated for MayJune $(r=0.75)$ and June-July $(r=0.66)$. However, plots of observed versus predicted mean annual summer water temperature (May-July and June-July) indicated that predicted values followed the general trends of observed values (Fig. 4). Therefore, it was reasonable to include predicted water temperatures for 2003-2013 in the body condition analyses. randomly split into training and testing data; $75 \%$ of data were allocated for model training and $25 \%$ were allocated for model testing. The most likely model was selected based on BIC analyses of 0.5 quantile models fitted with training data, as described for the time period analysis. Once the most likely model was selected, we estimated the weight-at-length for the 0.1 and 0.9 quantiles for each fish in the test data sets. We then calculated the proportion of fish in the test data set that fell within the 0.1-0.9 quantile weight intervals. For reasonably well performing models, about $80 \%$ of the test would fall within the $0.1-0.9$ quantile interval, $10 \%$ of predicted weights would be $<0.1$ quantile, and $10 \%$ would be greater than the predicted weight

305 for the 0.9 quantile. Finally, we plotted model parameters and 95\% confidence intervals across 306 quantiles 0.1-0.9. Reported model parameters are based on models fitted using all data.

\section{Results}




\section{Time period analysis}

Model results indicated that body condition of smallmouth bass and northern pike varied among time periods, with smallmouth bass experiencing greater proportional changes between time periods than northern pike (Figs. 5-9). The most likely weight-length model for smallmouth bass included terms for length, time period, and an interaction between time period and length (Table 2; Fig. 10). The most likely model for northern pike included terms for length, time period, and sex (Table 2; Fig. 11). Smallmouth bass body condition increased between each subsequent time period over the entire study period, and changes in smallmouth bass weight-atlength were greater between time periods 2 and 3 than between time periods 1 and 2 (Figs. 5 and 6). Changes in smallmouth bass weight-at-length were relatively homogenous across quantiles and the $470 \mathrm{~mm}$ length class experienced the greatest proportional increases in weight-at-length (Fig. 6). Northern pike weight-at-length decreased for quantiles $<0.7$ and increased for quantiles $>0.7$ between time periods one and two, increased across all quantiles between time periods two and three, and increased for quantiles $>0.4$ but decreased for quantiles $<0.3$ between time periods 1 and 3 (Figs.7-9). Parameter estimates for sex indicated that male northern pike were slightly heavier or similar in weight to female northern pike at a given length for all quantiles except the 0.1 quantile (Fig.11).

\section{Biological and environmental effects}

Ecological and environmental changes in the St. Lawrence River had varying effects on body condition of smallmouth bass and northern pike. The most likely weight-length model for smallmouth bass contained terms for length, presence of round goby, presence of dreissenid mussels, and an interaction between length and the presence of dreissenid mussels $\left(w_{i}=0.93\right.$; 
332 Table 3; Fig. 12). The most likely model for northern pike include terms for length, presence of 333 round goby, presence of dreissenid mussels, water temperature, northern pike CPU and sex $\left(w_{i}=\right.$ 334 0.88; Table 3; Fig. 3). Body condition of smallmouth bass was positively associated with the 335 presence of round goby across all quantiles (Fig. 12). For example, weight-at-length for median 336 condition smallmouth bass was about $13.5 \%(95 \% \mathrm{CI}=12.6-14.5 \%)$ greater when round goby 337 were present compared to when round goby were absent. Changes in body condition associated 338 with dreissenid mussels were also relatively homogenous across quantiles (Fig. 12), but dependent on smallmouth bass length; the presence of dreissenid mussels had a negative effect on body condition of the smallest fish sampled and positive effect on fish $>235 \mathrm{~mm}$ (Fig. 13). Similar to smallmouth bass, northern pike weight-at-length was positively associated with the 342 presence of round goby across all quantiles. However, unlike smallmouth bass, northern pike 343 weight-at-length was negatively associated with the presence of dreissenid mussels across all 344 quantiles (Fig. 3). Higher water temperatures were also associated with decreased weight-at345 length for northern pike across all quantiles (Fig. 3). On average, northern pike weight-at-length 346 decreased by $0.8 \%(95 \% \mathrm{CI}=-1.3--0.5 \%)$ per $1{ }^{\circ} \mathrm{C}$ increase in mean summer water temperature 347 across the range of mean summer water temperatures that occurred during 1982-2013 (13-17 $\left.348{ }^{\circ} \mathrm{C}\right)$. Finally, northern pike weight-at-length was inversely related to conspecific CPU for all but the lowest quantiles examined (Fig. 3) Testing of the weight-length models revealed that both models performed relatively well. $35181.1 \%$ of the smallmouth bass test data fell within the $0.1-0.9$ quantile range. $10.0 \%$ of weights352 at-length for smallmouth bass in the test data set were less than the expected value for the 0.1 353 quantile and $8.9 \%$ of weights-at-length were greater than the expected value for the 0.9 quantile. $35476.7 \%$ of the northern pike test data fell within the $0.1-0.9$ quantile range. $11.6 \%$ of weights-at- 
355 length for northern pike in the test data set were less than the expected value for the 0.1 quantile 356 and $11.7 \%$ of weights-at-length were greater than the expected value for the 0.9 quantile.

\section{Discussion}

Substantial ecological and environmental changes over the past 30 years have affected

361 The abiotic and biotic factors we examined were generally associated with increases in

362 smallmouth bass body condition, but had mixed and competing associations with body condition

363 of northern pike (e.g., presence of round goby was associated with increased body condition of

364 northern pike, but higher water temperatures were associated with a decrease in body condition).

365 The magnitude of changes across quantiles of body condition for smallmouth bass and northern

366 pike were likely related to interactions between biological and environmental changes in the St.

367 Lawrence River and each species' feeding and food preferences. The current ecological and

368 environmental conditions in the St. Lawrence River are favorable for smallmouth bass growth

369 and this was reflected in our body condition analyses. Clear water, abundant prey, and optimal

370 water temperature during the summer growing season have resulted in substantial increases in

371 weight-at-length for smallmouth bass across all quantiles of body condition. Recent

372 environmental changes have been less beneficial to northern pike than smallmouth bass and this

373 is likely due to its preference for cooler water temperatures and prey that occupy areas higher in

374 the water column. Variable changes in northern pike weight-at-length across quantiles indicates

375 that the best condition fish have benefitted from ecological changes, but the poorest condition

376 fish have been negatively affected. Of the variables examined, presence of round goby and

377 dreissenid mussels had the greatest effects on smallmouth bass body condition, and presence of 
378

379

380

381

382

383

384

round goby, presence of dreissenid mussels, and conspecific abundance had the greatest effects on northern pike body condition. Round goby and dreissenid mussels have dramatically altered Great Lakes ecosystems in a relatively short time period (Hecky et al. 2004; Campbell et al. 2009; Farrell et al. 2010). Dreissenid mussel invasion has resulted in increased water clarity and decreased pelagic productivity in the Great Lakes (Mills et al. 2003; Farrell et al. 2010), and round gobies have provided predatory fishes with an abundant benthic food resource (Kornis et al. 2012).

Water clarity and productivity can directly and indirectly affect feeding success, food availability, and subsequently body condition of predatory fishes. Summer Secchi depths in the St. Lawrence River were about 3 m before invasion of dreissenid mussels, but now frequently exceed $7 \mathrm{~m}$ (McCullough and Gordon 2014); therefore, increased water clarity associated with dreissenid mussel invasion may have benefitted feeding efficiency of visual predators such as smallmouth bass and northern pike (Sweka and Hartman 2003; Pierce et al. 2012). Smallmouth bass reaction distance to prey increases with decreasing turbidity (Sweka and Hartman 2003). Craig and Babaluk (1989) found a positive relationship between summer Secchi depth and northern pike body condition in 37 central Canadian lakes and hypothesized that water clarity positively affected the feeding abilities of northern pike. Although increased water clarity benefits the feeding capabilities of both smallmouth bass and northern pike, restructuring of energy pathways, associated with dreissenid mussel invasion, has favored benthic over pelagic productivity (Mills et al. 2003; Farrell et al. 2010; Murry and Farrell 2014) and likely explains the varying body condition responses between smallmouth bass and northern pike. The preferred prey of smallmouth bass are benthic species, which may have benefitted from invasion of dreissenid mussels, while the preferred prey of northern pike occupy areas higher in the water 
401 column and may have been negatively affected by decreased pelagic productivity. For example, 402 abundances of yellow perch (Perca flavescens) and alewife (Alosa pseudoharengus) decreased

403 substantially during the 1982-1992 time period and have remained at low levels since then 404 (McCullough and Gordon 2014).

Increased condition of smallmouth bass and northern pike since 2005 illustrates a benefit

406 of the non-native round goby. Dreissenid mussels are a primary prey item of round goby

407 (French III and Jude 2001; Johnson et al. 2005; Taraborelli 2010) and round goby are heavily

408 consumed by a variety predators in the Great Lakes-St. Lawrence River (Kornis et al. 2012),

409 including smallmouth bass and northern pike (Reyjol 2010; Taraborelli 2010; Crane and

410 Einhouse 2016). Therefore, invasion by round goby created an energy pathway that allowed for

411 transfer of energy from dreissenid mussels to higher trophic levels; thus, reversing some of the

412 negative effects of decreased pelagic productivity on predatory fishes such as northern pike.

413 (Johnson et al. 2005). Crane et al. (2015) documented substantial increases in body condition of 414 smallmouth bass and yellow perch (Perca flavescens) following invasions in Lakes Erie and

415 Ontario by round goby, but concluded that availability of round goby as a new prey had minimal 416 effects on burbot (Lota lota) and walleye (Sander vitreus) body condition. Crane et al. (2015)

417 hypothesized that predator-prey habitat overlap, predator-prey size relationships, and feeding 418 strategies explained among species differences in body condition responses. Although both 419 northern pike and smallmouth bass experienced increases in weight-at-length following invasion 420 of the St. Lawrence River by round goby, greater increases were observed for smallmouth bass. 421 The smallmouth bass has a higher probability of encountering round goby compared to northern

422 pike due to differences in feeding strategies between the species and sedentary nature of round 423 goby (Kornis et al. 2012). Because the northern pike is a sit-and-wait predator, it less likely to 
424 encounter the sedentary round goby compared to the smallmouth bass, which more actively 425 searches for prey.

Because density dependence in fishes is the result of competition (Diana 2004), changes

427 in prey availability following invasion of the St. Lawrence River by dreissenid mussels and 428 round goby likely altered any previously existing relationships between conspecific abundance 429 and body condition of smallmouth bass. For example, the availability of round goby as an 430 abundant food item likely limited competition for food and density dependent effects on body 431 condition of smallmouth bass during a time of increased abundance of smallmouth bass.

432 Smallmouth bass weight-at-length was greatest during 2005-2013 (post-dreissenid mussel, post433 round goby) despite average annual CPU increasing 90\% between the 1993-2004 and 2005-2013 434 time periods (McCullough and Gordon 2014). Although the increase in CPU may partially be 435 attributed to increased catchability of faster growing smallmouth bass (McCullough and Gordon 436 2014), it is unlikely that the smallmouth bass population declined from the 1993-2004 to the 437 2005-2013 time period and allowed for compensatory growth. Round goby has limited density 438 dependent effects on body condition in other Great Lakes waters as well. Smallmouth bass and 439 yellow perch body condition and smallmouth bass growth increased after invasion of Lake Erie 440 by round goby, despite increased abundance of both species immediately following round goby 441 invasion (Crane et al. 2015; Crane and Einhouse 2016). In contrast to smallmouth bass, northern 442 pike weight-at-length was affected by conspecific abundance. Northern pike body condition was 443 lowest during 1993-2004 (post-dreissenid mussel, pre-round goby) despite decreased abundance 444 of conspecifics compared to the 1982-1992 time period (pre-dreissenid mussel, pre-round goby). 445 However, decreased abundance of northern pike during 1993-2004 may have prevented further 446 decreases in weight-at-length associated with dreissenid mussel invasion. Recent increases in 
447 body condition may also be partially attributed to low northern pike abundance during 2005-

448 2013. Staton et al. (2014) observed that body condition of yellow perch $>150 \mathrm{~mm}$ (Saginaw

449 Bay, Lake Huron) was significantly related to relative abundance of yellow perch, but because

450 the relationship was weak the authors suggested that invasive species driven changes in the

451 Saginaw Bay food web also affected body condition yellow perch.

452 Summer water temperature limited the body condition of northern pike, but not

453 smallmouth bass in the St. Lawrence River. The northern pike is considered a coolwater species

454 and body condition is inversely related to water temperature across its range (Doyon et al. 1988).

455 Water temperature in the St. Lawrence River frequently exceeds the optimal temperature for 456 growth in mass of northern pike $\left(19^{\circ} \mathrm{C}\right.$; Casselman 1978). The smallmouth bass is classified as

457 a warmwater species and summer water temperature in the St. Lawrence frequently overlaps the

458 optimal temperature for smallmouth bass growth $\left(22{ }^{\circ} \mathrm{C}\right.$; Whitledge et al. 2002). From 1993-

4592008 July monthly mean water temperature was $>19{ }^{\circ} \mathrm{C}$ during 15 years and $>20{ }^{\circ} \mathrm{C}$ during 8

460 years $\left(\right.$ mean $=20.3{ }^{\circ} \mathrm{C}$; see National Oceanic Atmospheric Administration, Alexandria Bay, New

461 York, U.S.A. Coastal-Marine Automated Network Station ABAN6; available online at:

462 http://www.ndbc.noaa.gov/station_page.php?station=aban6 for water temperature data; accessed

4637 April 2015). Additionally, summer water temperature in the St. Lawrence River generally

464 peaks in August, and August water temperature averaged $21.9^{\circ} \mathrm{C}$ during 1993 through 2008.

465 Increasing summer water temperature associated with climate change in the Great Lakes Basin

466 (Trumpickas et al. 2009) will result in increased physiological stress and limit body condition of

467 northern pike. However, potential temperature related decreases in weight-at-length may be

468 offset by prey availability because water temperature and ration interact to affect growth (Diana

469 2004). The 2005-2013 time period was the warmest time period in this study, but northern pike 
470 weight-at-length was greater during 2005-2013, compared to the 1982-1992 and 1993-2004 time

471 periods. High abundance of round goby and low abundance of northern pike may have mediated

472 effects of recent warm water temperatures on northern pike body condition.

473 Previous research has suggested energetic costs to smallmouth bass associated with the

474 presence of a new, highly abundant egg predator (Steinhardt et al. 2005); however, round goby

475 did not affect the body condition of male nest guarding smallmouth bass in this study. Crane and

476 Einhouse (2016) also found that changes in Lake Erie smallmouth bass growth following round

477 goby invasion did not vary between males and females. Differences in the temporal proximity

478 between nest-guarding and collection of fish may explain the discrepancy between our results

479 and the findings of Steinhardt et al. (2005). Smallmouth bass in this study were collected 1-2

480 months after the spawning season; whereas, Steinhardt et al. (2005) collected fish while they

481 were still guarding free-swimming juveniles. Energetic costs associated with nest-guarding in the

482 presence of round goby are likely short-term, and the hyperabundance of round goby may allow

483 for smallmouth bass to quickly recover depleted energy reserves. However, fish in this study

484 were collected several weeks after nest-guarding finished; therefore, we were unable to account

485 for any poor condition fish that died as the result of energetic costs associated with reproduction.

486

Rennie et al. (2009) suggested that simple before-after studies of the effects of aquatic

487 invaders on fish condition may lead to spurious results if confounding variables are present.

488 Although our analysis was more complex than a simple before-after study, additional

489 limnological and prey abundance data would have improved our mechanistic understanding of

490 the relationships between biological and environmental conditions and body condition of

491 predatory fishes. Long-term data sets for basic limnological variables such as nutrient and

492 chlorophyll concentrations are incomplete for the St. Lawrence River. Similarly, a long-term 
493 continuous, single station water temperature data set was not available, which resulted in a need

494 to model water temperature for 2003-2013. Unlike other areas of the Great Lakes, annual prey

495 fish assessments are limited to seining and gill netting in the St. Lawrence River. Increased

496 availability of data for basic limnological and biological variables will allow for a better

497 understanding of how important sport fishes will respond to a changing ecosystem.

498

499

Acknowledgements

500

501

502

503

504

505

506

507

508

509

510

511

512

513

514

515

516

We would like to thank the many dedicated NYSDEC employees who were integral in collecting and maintaining the data used in this study. We especially thank Russell McCullough, David Gordon, and Rodger Klindt for providing the fish data and Irene Mazzocchi and Adam Bleau for providing the double-crested cormorant data. We also thank Yong Chen, Brian S. Cade, and two anonymous reviewers for their comments that improved this manuscript.

\section{References}

Blackwell, B.G., Brown, M.L., and Willis, D.W. 2000. Relative weight ( $W r)$ status and current use in fisheries assessment and management. Rev. Fish. Sci. 8(1): 1-44. doi:10.1080/10641260091129161

Cade, B.S., Terrell, J.W., and Porath, M.T. 2008. Estimating fish body condition with quantile regression. N. Am. J. Fish. Manage. 28(6): 349-359. doi:10.1577/M07-048.1

Cade, B.S., Terrell, J.W. and Neely, B.C. 2011. Estimating geographic variation in allometric growth and body condition of Blue Suckers with quantile regression. Trans. Am. Fish. Soc. 140(6): 1657-1669. doi:10.1080/00028487.2011.641885

Campbell, L.M., Thacker, R., Barton, D., Muir, D.C.G., Greenwood, D., and Hecky, R.E. 2009. Re-engineering the Lake Erie littoral food web: the trophic function of non-indigenous 
517

518

519

520

521

522

523

524

525

526

527

528

529

530

531

532

533

534

535

536

537

538

539

Ponto-Caspian species. J. of Great Lakes Res. 35(2): 224-231.

doi:10.1016/j.jglr.2009.02.002

Casselman, J.M. 1978. Effects of environmental factors on growth, survival, activity, and exploitation of northern pike. Am. Fish. Soc. Publ. 11: 114-128.

Craig, J.F., and J.A. Babaluk. 1989. Relationship of condition of walleye (Stizostedion vitreum) and pike (Esox lucius) to water clarity, with special reference to Dauphin Lake, Manitoba. Can. J. Fish. Aquat. Sci. 46(9): 1581-1586. doi:10.1139/f89-201

Crane, D.P., and D.W. Einhouse. 2016. Changes in growth and diet of smallmouth bass following invasion of Lake Erie by the round goby. J. of Great Lakes Res. 42(2): 405412. doi:10.1016/j.jglr.2015.12.005

Crane, D.P., Farrell, J.M., Einhouse, D.W., Lantry, J.R., and Markham, J.L. 2015. Trends in body condition of native piscivores following invasion of Lakes Erie and Ontario by the round goby. Freshwater Biol. 60(1): 111-124. doi:10.1111/fwb.12473

Diana, J.S. 2004. Biology and Ecology of Fishes, 2nd ed. Cooper Publishing Group, Traverse City, Michigan.

Doyon, J.F., Downing, J.A., and. Magnin, E. 1988. Variation in the condition of northern pike, Esox lucius. Can. J. Fish. Aquat. Sci. 45(3): 479-483. doi:10.1139/f88-057

Dutil, J.-D., and Lambert, Y. 2000. Natural mortality from poor condition in Atlantic cod (Gadus morhua). Can. J. Fish. Aquat. Sci. 57(4): 826-836. doi:10.1139/f00-023

Farrell, J.M., Holeck, K.T., Mills, E.L., Hoffman, C.E., and Patil, V.J., 2010. Recent ecological trends in lower trophic levels of the international section of the St. Lawrence River: a comparison of the 1970s to the 2000s. Hydrobiologia. 647(1): 21-33. doi: $10.1007 /$ s10750-009-0003-7 
540 French, J.R.P., III, and Jude, D.J. 2001. Diets and diet overlap of nonindigenous gobies and

541

542

543

544

545

546

547

548

549

550

551

552

553

554

555

556

557

558

559

560

small benthic native fishes co-inhabiting the St. Clair River, Michigan. J. Great Lakes

Res. 27(3): 300-311. doi:10.1016/S0380-1330(01)70645-4

Fox, J., Weisberg, S. 2016. An R Companion to Applied Regression. R package version 2.1-2. Available: http://CRAN.R-project.org/package=car

Gabelhouse, D.W., Jr. 1984. A length-categorization system to assess fish stocks. N. Am. J. Fish. Manage. 4(3): 273-285. doi:10.1577/1548-8659(1984)4<273:ALSTAF>2.0.CO;2

Johnson, T. B., Bunnell, D.B., and C. T. Knight. 2005. A potential new energy pathway in central Lake Erie: the Round Goby connection. J. Great Lakes Res. 31(Supplement 2): 238-251. doi:10.1016/S0380-1330(05)70317-8

Johnson, D.W. 2008. Combined effects of condition and density on post-settlement survival and growth of a marine fish. Oecologia. 155(1): 43-52. doi:10.1007/s00442-007-0882-0

Johnson, J.H., Farquhar, J.F., Klindt, R.M., Mazzocchi, I., and Mathers, A. 2015. From yellow perch to round goby: A review of double-crested cormorant diet and fish consumption at Three St. Lawrence River Colonies, 1999-2013. J. Great Lakes Res. 41(1): 259-265. doi:10.1016/j.jglr.2014.12.011.

Koenker R. 2016. quantreg: Quantile Regression. R package version 5.26. Available: http://CRAN.R-project.org/package=quantreg

Kornis M.S., Mercado-Silva N., and Vander Zanden M.J. 2012. Twenty years of invasion: a review of Round Goby Neogobius melanostomus biology, spread and ecological implications. J. Fish Biol. 80(2): 235-285. doi:10.1111/j.1095-8649.2011.03157.x 
561 Link, W.A., and Barker, R.J., 2006. Model weights and the foundations of multimodel

562

563

564

565

566

567

568

569

570

571

572

573

574

575

576

577

578

579

580

581

582

583

inference. Ecology. 87(10): 2626-2635. doi:10.1890/0012-

9658(2006)87[2626:MWATFO]2.0.CO;2

Marshall, C.T., and Frank, K.T. 1999. The effect of interannual variation in growth and condition on haddock recruitment. Can. J. Fish. Aquat. Sci. 56(3): 347-355. doi:10.1139/f99-019

Marwitz, T.D. and Hubert, H.A. 1997. Trends in relative weight of walleye stocks in Wyoming reservoirs. N. Am. J. Fish. Manage. 17(1): 44-53. doi:10.1577/1548-

8675(1997)017<0044:TIRWOW>2.3.CO;2

McCullough, R.D, and Gordon D.J. 2014. Thousand Islands warmwater fish stock assessment. 2013 NYSDEC Annual Report, Bureau of Fisheries Lake Ontario Unit and St. Lawrence River Unit to the Great Lakes Fishery Commission's Lake Ontario Committee, Albany.

Mills, E.L., Casselman, J.M., Dermott, R., Fitzsimons, J.D., Gal, G., Holeck, K.T., Hoyle, J.A., Johannsson, O.E., Lantry, B.F., and Makarewicz, J.C. 2003. Lake Ontario: food web dynamics in a changing ecosystem (1970-2000). Can. J. Fish. Aquat. Sci. 60(): 471-490. doi: $10.1139 / \mathrm{f03}-033$

Murry B.A., and Farrell J.M., 2014. Resistance of the size structure of the fish community to ecological perturbations in a large river ecosystem. Freshwater Biol. 59(1): 155-167. doi: 10.1111/fwb. 12255

Murtaugh, P.A., 2014. In defense of $P$ values. Ecology. 95(3): 611-617. doi: 10.1890/13-0590.1

O’Brien, R.M., 2007. A caution regarding rules of thumb for variance inflation factors. Qual. Quant. 41(5): 673-690. doi:10.1007/s11135-006-9018-6

Pierce R.B. 2012. Northern pike ecology, conservation and management history. University of Minnesota Press, Minneapolis, M.N. 
Pope, K.L., and Kruse, C.G. 2007. Condition. In Analysis and interpretation of freshwater fisheries data. Edited by C.S. Guy and M.L. Brown, American Fisheries Society, Bethesda, M.D. pp. 423-471

Porath M.T., and Peters, E.J. 1997. Use of Walleye relative weights $(\mathrm{Wr})$ to assess prey availability. N. Am. J. Fish. Manage. 17(3): 628-637. doi:10.1577/15488675(1997)017<0628:UOWRWW>2.3.CO;2

R Core Team, 2016. R: A language and environment for statistical computing. R Foundation for Statistical Computing, Vienna, Austria. Available: http://www.R-project.org/

Raftery, A.E. 1995. Bayesian Model Selection in Social Research. Sociological Methodology. 25: 111-163. doi: $10.2307 / 271063$

Rennie, M.D., Sprules, W.G., and Johnson, T.B. 2009. Factors affecting the growth and condition of lake whitefish (Coregonus clupeaformis). Can. J. Fish. Aquat. Sci. 66(12): 2096-2108. doi:10.1139/F09-139.

Reyjol, Y., Brodeur, P., Mailhot, Y., Mingelbier, M., and Dumont, P., 2010. Do native predators feed on non-native prey? The case of round goby in a fluvial piscivorous fish assemblage. J. Great Lakes Res. 36(4): 618-624. doi:10.1016/j.jglr.2010.09.006

Schwarz, G., 1978. Estimating the Dimension of a Model. Ann. Stat. 6(2): 461-464.

Staton, J.M., Roswell, C.R., Fielder, D.G., Thomas, M.V., Pothoven, S.A., and Höök, T.O., 2014. Evaluating differences in condition of yellow perch in Saginaw Bay, Lake Huron (1970-2011). J. Great Lakes Res. 40(1): 139-147. doi:10.1016/j.jglr.2014.02.021

Steinhart, G.B., Sandrene, M.E., Weaver, S., Stein, R.A., and Marschall, E.A. 2005. Increased parental care cost for nest-guarding fish in a lake with hyperabundant nest predators. Behav. Ecol. 16(2): 427-434. doi:10.1093/beheco/ari006. 
607 Sweka, J.A., and Hartman, K.J. 2003. Reduction of reactive distance and foraging success in 608 609 610 611 smallmouth bass, Micropterus dolomieu, exposed to elevated turbidity levels. Environ. Biol. of Fishes. 67(4): 341-347. doi:10.1023/A:1025835031366

Taraborelli, A.C., Fox, M.G., Schaner, T., and Johnson, T.B., 2009. Density and habitat use by the round goby (Apollonia melanostoma) in the Bay of Quinte, Lake Ontario. J. Great Lakes Res. 35(2): 266-271. doi:10.1016/j.jglr.2010.07.011

Trumpickas, J., Shuter, B.J., and Minns, C.K. 2009. Forecasting impacts of climate change on Great Lakes surface water temperatures. J. Great Lakes Res. 35(3): 454-463. doi:10.1016/j.jglr.2009.04.005.

VanDeValk, A.J., Forney, J.L., and Jackson, J.R. 2008. Relationships between relative weight, prey availability, and growth of walleyes in Oneida Lake, New York. N. Am. J. Fish. Manage. 28(6):1868-1875. doi:10.1577/M08-064.1

Wagenmakers, E.-J., and Farrell, S. 2004. AIC model selection using Akaike weights. Psychon. Bull. \& Rev. 11(1): 192-196. doi:10.3758/BF03206482

Whitledge, G.W., Hayward, R.S. and Rabeni, C.F. 2002. Effects of temperature on specific daily metabolic demand and growth scope of sub-adult and adult smallmouth bass. J. Freshwater Ecol. 17(3): 353-361. doi:10.1080/02705060.2002.9663908.

Willis, D. W. 1989. Proposed standard length-weight equation for northern pike. N. Am. J. Fish. Manage. 9(2): 203-208. doi:10.1577/1548-8675(1989)009<0203:PSLWEF>2.3.CO;2

Zuur, A.F., Ieno, E.N., and Elphick, C.S., 2010. A protocol for data exploration to avoid common statistical problems. Methods Ecol Evol. 1(1): 3-14. doi:10.1111/j.2041210X.2009.00001.x 
Table 1. Sample sizes of male and female smallmouth bass and northern pike used for body condition analyses.

\begin{tabular}{llrrrr}
\hline Species & Sex & $1982-1992$ & $1993-2004$ & $2005-2013$ & Species total \\
\hline Smallmouth bass & M & 728 & 383 & 559 & 4499 \\
& F & 1110 & 690 & 1029 & \\
Northern pike & M & 518 & 270 & 176 & 2623 \\
& F & 803 & 589 & 267 & \\
\hline
\end{tabular}

630

631 
Table 2. List of competing $\log _{10}$ transformed median weight-length models used to investigate changes in body condition of smallmouth bass and northern pike during three ecologically different time periods in the Thousand Islands region of the St. Lawrence River. Candidate models included terms for length (TL), time period (time), sex, and one-way interactions between variables. Models were ranked using Bayesian information criterion (BIC), $\triangle \mathrm{BIC}$, and Schwartz weights $\left(w_{i}\right)$, with the most likely model corresponding to the lowest BIC and greatest $w_{i}$.

\begin{tabular}{|c|c|c|c|}
\hline Model & $\mathrm{BIC}$ & $\triangle \mathrm{BIC}$ & $w_{i}$ \\
\hline \multicolumn{4}{|c|}{ Smallmouth bass } \\
\hline $\log _{10}(\mathrm{TL})$, time, $\log _{10}(\mathrm{TL}) \times$ time & -15606.0 & 0.0 & 0.99 \\
\hline $\log _{10}(\mathrm{TL})$, time, sex, $\log _{10}(\mathrm{TL}) \mathrm{x}$ time & -15597.6 & 8.4 & 0.01 \\
\hline $\log _{10}(\mathrm{TL})$, time, sex, $\log _{10}(\mathrm{TL}) \mathrm{x}$ time, time $\mathrm{x}$ sex & -15586.2 & 19.8 & $<0.01$ \\
\hline $\log _{10}(\mathrm{TL})$, time & -15575.1 & 30.9 & $<0.01$ \\
\hline $\log _{10}(\mathrm{TL})$, time, sex & -15566.7 & 39.3 & $<0.01$ \\
\hline $\log _{10}(\mathrm{TL})$ & -13433.2 & 2172.9 & $<0.01$ \\
\hline $\log _{10}(\mathrm{TL}), \operatorname{sex}, \log _{10}(\mathrm{TL}) \mathrm{x}$ sex & -13429.9 & 2176.1 & $<0.01$ \\
\hline $\log _{10}(\mathrm{TL})$, sex & -13426.2 & 2179.8 & $<0.01$ \\
\hline \multicolumn{4}{|l|}{ Northern pike } \\
\hline $\log _{10}(\mathrm{TL})$, time, sex & -7709.6 & 0.0 & 0.98 \\
\hline $\log _{10}(\mathrm{TL})$, time & -7700.8 & 8.8 & 0.01 \\
\hline $\log _{10}(\mathrm{TL})$, time, sex, $\log _{10}(\mathrm{TL}) \mathrm{x}$ time & -7699.8 & 9.8 & 0.01 \\
\hline $\log _{10}(\mathrm{TL})$, time, $\log _{10}(\mathrm{TL}) \times$ time & -7690.9 & 18.8 & $<0.01$ \\
\hline $\log _{10}(\mathrm{TL})$, time, sex, $\log _{10}(\mathrm{TL}) \mathrm{x}$ time, time $\mathrm{x}$ sex & -7685.3 & 24.4 & $<0.01$ \\
\hline $\log _{10}(\mathrm{TL})$, sex & -7677.2 & 32.5 & $<0.01$ \\
\hline $\log _{10}(\mathrm{TL}), \operatorname{sex}, \log _{10}(\mathrm{TL}) \mathrm{x}$ sex & -7673.2 & 36.5 & $<0.01$ \\
\hline $\log _{10}(\mathrm{TL})$ & -7670.4 & 39.2 & $<0.01$ \\
\hline
\end{tabular}


Table 4. List of competing $\log _{10}$ transformed median weight-length models used to investigate the effects of biological and environmental variables on body condition of smallmouth bass and northern pike in the Thousand Islands region of the St. Lawrence River. Candidate models included terms for length (TL), presence of round goby (RG), presence of dreissenid mussels (DM), mean summer water temperture (temp), abundance of conspecifics (CPU), sex (northern pike only), and one-way interactions between variables. Models were ranked using Bayesian information criterion (BIC), $\Delta \mathrm{BIC}$, and Schwartz weights $\left(w_{i}\right)$, with the most likely model corresponding to the lowest BIC and greatest $w_{i}$.

\begin{tabular}{|c|c|c|c|}
\hline Model & $\mathrm{BIC}$ & $\Delta \mathrm{BIC}$ & $w_{i}$ \\
\hline \multicolumn{4}{|l|}{ Smallmouth bass } \\
\hline $\log _{10}(\mathrm{TL})+\mathrm{RG}+\mathrm{DM}+\log _{10}(\mathrm{TL}) \mathrm{x} \mathrm{DM}$ & -12445.6 & 0.0 & 0.93 \\
\hline $\log _{10}(\mathrm{TL})+\mathrm{RG}+\mathrm{DM}+\log _{10}(\mathrm{TL}) \times \mathrm{RG}+\log _{10}(\mathrm{TL}) \times \mathrm{DM}$ & -12438.7 & 6.9 & 0.03 \\
\hline $\log _{10}(\mathrm{TL})+\mathrm{RG}+\mathrm{DM}+\log _{10}($ temp $)+\log _{10}(\mathrm{TL}) \times \mathrm{RG}+\log _{10}(\mathrm{TL}) \times \mathrm{DM}$ & -12437.1 & 8.5 & 0.01 \\
\hline $\log _{10}(\mathrm{TL})+\mathrm{RG}+\mathrm{DM}+\log _{10}(\mathrm{CPU})+\log _{10}($ temp $)+\log _{10}(\mathrm{TL}) \times \mathrm{DM}$ & -12437.1 & 8.5 & 0.01 \\
\hline $\log _{10}(\mathrm{TL})+\mathrm{RG}+\mathrm{DM}+\log _{10}(\mathrm{CPU})+\log _{10}(\mathrm{TL}) \times \mathrm{DM}+\log _{10}(\mathrm{CPU}) \times \mathrm{RG}$ & -12436.8 & 8.8 & 0.01 \\
\hline $\log _{10}(\mathrm{TL})+\mathrm{RG}+\mathrm{DM}+\log _{10}(\mathrm{CPU})+\log _{10}(\mathrm{TL}) \mathrm{xG}+\log _{10}(\mathrm{TL}) \mathrm{xM}$ & -12430.9 & 14.7 & $<0.01$ \\
\hline $\log _{10}(\mathrm{TL})+\mathrm{RG}+\mathrm{DM}+\log _{10}(\mathrm{CPU})+\log _{10}(\mathrm{temp})+\log _{10}(\mathrm{TL}) \times \mathrm{RG}+\log _{10}(\mathrm{TL}) \times \mathrm{DM}+\log _{10}(\mathrm{CPU}) \times \mathrm{RG}$ & -12430.6 & 15.0 & $<0.01$ \\
\hline $\log _{10}(\mathrm{TL})+\mathrm{RG}+\mathrm{DM}$ & -12409.8 & 35.8 & $<0.01$ \\
\hline $\log _{10}(\mathrm{TL})+\mathrm{RG}+\mathrm{DM}+\log _{10}(\mathrm{CPU})+\log _{10}(\mathrm{temp})+\log _{10}(\mathrm{TL}) \mathrm{xG}+\log _{10}(\mathrm{CPU}) \times \mathrm{RG}$ & -12403.8 & 41.8 & $<0.01$ \\
\hline $\log _{10}(\mathrm{TL})+\mathrm{RG}+\mathrm{DM}+\log _{10}(\mathrm{CPU})+\log _{10}(\mathrm{temp})+\log _{10}(\mathrm{CPU}) \mathrm{xG}$ & -12403.4 & 42.2 & $<0.01$ \\
\hline $\log _{10}(\mathrm{TL})+\mathrm{RG}+\mathrm{DM}+\log _{10}(\mathrm{CPU})+\log _{10}(\mathrm{TL}) \mathrm{xG}+\log _{10}(\mathrm{CPU}) \times \mathrm{RG}$ & -12402.5 & 43.1 & $<0.01$ \\
\hline $\log _{10}(\mathrm{TL})+\mathrm{RG}+\mathrm{DM}+\log _{10}(\mathrm{CPU})+\log _{10}(\mathrm{temp})$ & -12402.1 & 43.5 & $<0.01$ \\
\hline $\log _{10}(\mathrm{TL})+\mathrm{RG}+\mathrm{DM}+\log _{10}(\mathrm{CPU})$ & -12401.8 & 43.8 & $<0.01$ \\
\hline $\log _{10}(\mathrm{TL})+\mathrm{RG}+\log _{10}(\mathrm{CPU})+\log _{10}(\mathrm{CPU}) \mathrm{xG}$ & -12396.8 & 48.8 & $<0.01$ \\
\hline $\log _{10}(\mathrm{TL})+\mathrm{RG}+\log _{10}(\mathrm{CPU})+\log _{10}(\mathrm{TL}) \times \mathrm{RG}+\log _{10}(\mathrm{CPU}) \times \mathrm{RG}$ & -12394.7 & 50.9 & $<0.01$ \\
\hline $\log _{10}(\mathrm{TL})+\mathrm{RG}+\log _{10}(\mathrm{CPU})$ & -12383.8 & 61.8 & $<0.01$ \\
\hline $\log _{10}(\mathrm{TL})+\mathrm{RG}$ & -12379.3 & 66.3 & $<0.01$ \\
\hline $\log _{10}(\mathrm{TL})+\mathrm{RG}+\log _{10}(\mathrm{TL}) \times \mathrm{RG}$ & -12377.8 & 67.8 & $<0.01$ \\
\hline $\log _{10}(\mathrm{TL})+\mathrm{RG}+\log _{10}(\mathrm{CPU})+\log _{10}($ temp $)$ & -12376.6 & 68.9 & $<0.01$ \\
\hline $\log _{10}(\mathrm{TL})+\mathrm{RG}+\log _{10}($ temp $)$ & -12374.0 & 71.6 & $<0.01$ \\
\hline $\log _{10}(\mathrm{TL})+\mathrm{RG}+\log _{10}($ temp $)+\log _{10}(\mathrm{TL}) \mathrm{xG}$ & -12372.5 & 73.1 & $<0.01$ \\
\hline
\end{tabular}




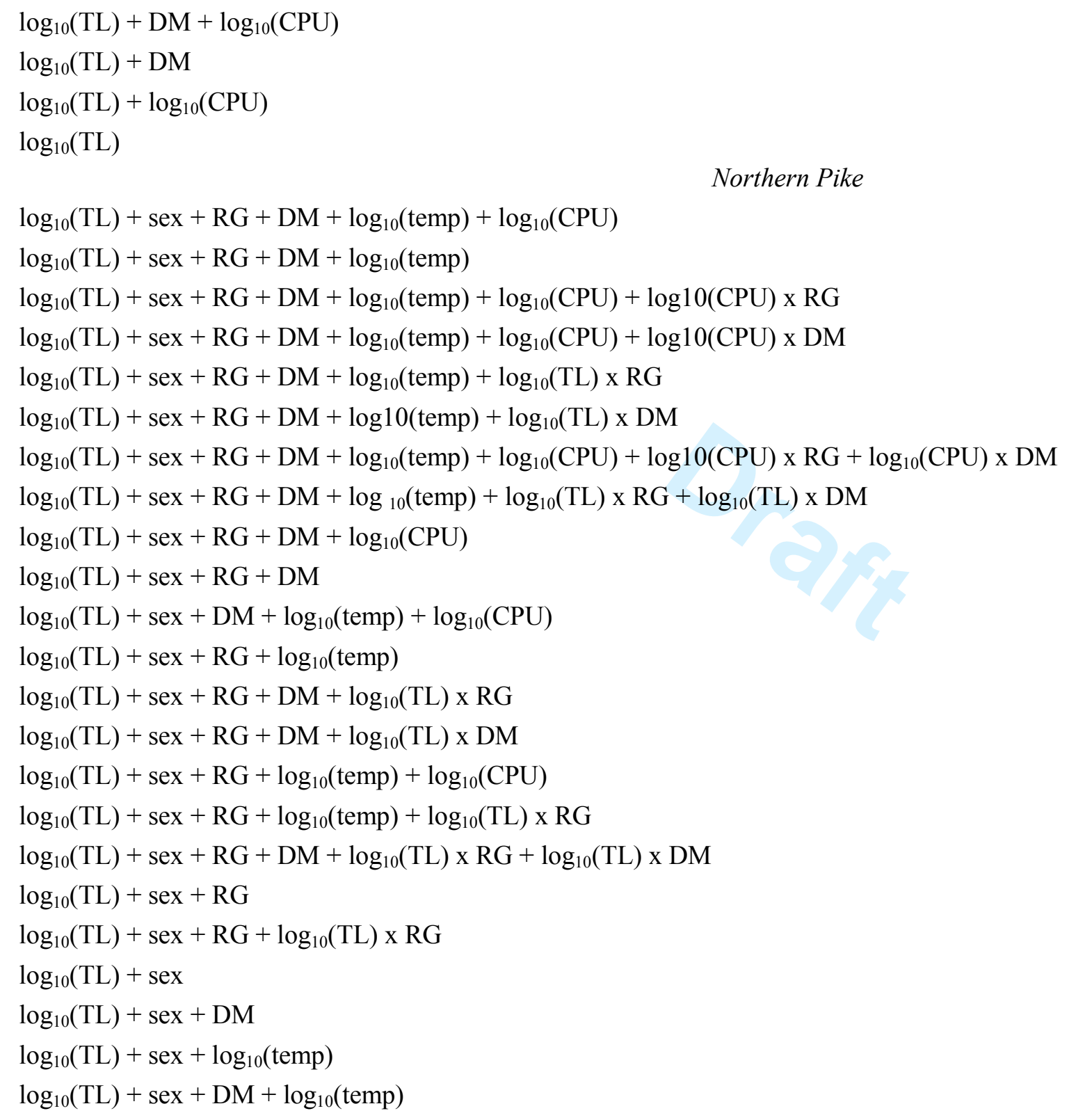

$\begin{array}{rrr}-11880.9 & 564.7 & <0.01 \\ -11575.3 & 870.3 & <0.01 \\ -10848.4 & 1597.2 & <0.01 \\ -10793.1 & 1652.5 & <0.01\end{array}$

$\begin{array}{lll}-5830.8 & 0.0 & 0.56\end{array}$

$\begin{array}{lll}-5829.1 & 1.6 & 0.25\end{array}$

$\begin{array}{lll}-5828.0 & 2.8 & 0.14\end{array}$

$\begin{array}{lll}-5824.0 & 6.7 & 0.02\end{array}$

$\begin{array}{lll}-5823.7 & 7.1 & 0.02\end{array}$

$\begin{array}{lll}-5822.9 & 7.9 & 0.01\end{array}$

$\begin{array}{lll}-5820.5 & 10.3<0.01\end{array}$

$\begin{array}{lll}-5816.7 & 14.1<0.01\end{array}$

$\begin{array}{llll}-5815.4 & 15.4<0.01\end{array}$

$-5815.2 \quad 15.6<0.01$

$\begin{array}{llll}-5812.6 & 18.1<0.01\end{array}$

$\begin{array}{llll}-5810.1 & 20.6<0.01\end{array}$

$\begin{array}{lll}-5808.8 & 22.0 & <0.01\end{array}$

$\begin{array}{llll}-5808.7 & 22.1<0.01\end{array}$

$\begin{array}{lll}-5808.2 & 22.6 & <0.01\end{array}$

$\begin{array}{lll}-5804.0 & 26.8<0.01\end{array}$

$\begin{array}{llll}-5801.7 & 29.1<0.01\end{array}$

$\begin{array}{lll}-5797.1 & 33.6<0.01\end{array}$

$\begin{array}{lll}-5790.9 & 39.8<0.01\end{array}$

$\begin{array}{lll}-5790.6 & 40.1<0.01\end{array}$

$\begin{array}{lll}-5790.5 & 40.3<0.01\end{array}$

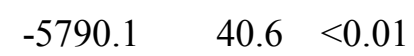

$\begin{array}{lll}-5788.3 & 42.5<0.01\end{array}$ 
$\log _{10}(\mathrm{TL})+\operatorname{sex}+\log _{10}($ temp $)+\log _{10}(\mathrm{CPU})$

$-5783.6$

$47.2<0.01$

$\log _{10}(\mathrm{TL})+\mathrm{sex}+\mathrm{DM}+\log _{10}(\mathrm{TL}) \mathrm{x} \mathrm{DM}$

$-5783.2$

$47.6<0.01$

$\log _{10}(\mathrm{TL})+\mathrm{sex}+\log _{10}(\mathrm{CPU})$

$-5783.1$

$47.7<0.01$

638

639

640

641

642

643

644

645

646

647

648

649

650 
651 Fig. 1. Map of the Thousand Islands region of the upper St. Lawrence River. Basemap from Esri

652 Inc., 2014.

Fig. 2. Ecological variables incorporated in analyses of body condition of smallmouth bass and northern pike from the Thousand Islands region of the St. Lawrence River, NY. (A)

Fig. 3. Biological and environmental variable analysis - Parameter estimates ( $95 \%$ CI's) for quantile regression weight-length ( $\log 10$-transformed) models for northern pike collected in the Thousand Islands Region of the St. Lawrence River (1982-2013). Variables included in the final models were selected using Bayesian information criterion. Candidate models included terms for $\log 10$ total length (TL), presence of round goby 
673

674

675

676

677

678

679

680

681

682

683

684

685

686

687

688

689

690

691

692

693

694

695

(RG), presence of dreissenid mussels (DM), mean summer water temperature (temp), abundance of conspecifics (CPU), sex and one way interactions between variables.

Fig. 4. Observed versus predicted water temperature for the St. Lawrence River near Maitland, Ontario (1965-2002). Water temperatures for May-July (A) were used in analyses of northern pike body condition, and water temperatures for June-July (B) were used in analyses of smallmouth bass body condition. Predicted water temperature was based on an exponential model of observed mean monthly water temperature in the St. Lawrence River and mean monthly air temperature at the Watertown International Airport in Watertown, New York.

Fig. 5. Multiplicative changes (95\% CI's) in smallmouth bass weight-at-length from the St. Lawrence River during three ecologically distinct time periods. Time period $1=1982$ 1992; time period $2=1993-2004$; time period $3=2005-2013$.

Fig. 6. Predicted weight-at-length (95\% CI's) across quantiles $0.1-0.9$ for specified length classes of smallmouth bass from the Thousand Islands region of the St. Lawrence River. Weight-at-length is displayed for three ecologically distinct time periods. Smallmouth bass weight-length models were based on a sample of 4499 fish collected during 19822013.

Fig. 7. Multiplicative changes (95\% CI's) in northern pike weight-at-length from the St. Lawrence River during three ecologically distinct time periods. Although weight-at- 
696

697

698

699

700

701

702

703

704

705

706

707

708

709

710

711

712

713

714

715

716

717

718

length differed between male and female northern pike, changes in weight-at-length between time periods were not dependent on sex. Therefore, the reported multiplicative changes in weight-at-length apply to male and female northern pike. Time period $1=$ 1982-1992; time period $2=1993-2004$; time period $3=2005-2013$.

Fig. 8. Predicted weight-at-length ( $95 \%$ CI's) across quantiles $0.1-0.9$ for specified length classes of male northern pike from the Thousand Islands region of the St. Lawrence River. Weight-at-length is displayed for three ecologically distinct time periods. Northern pike weight-length models were based on a sample of 2623 fish collected during 1982-2013.

Fig. 9. Predicted weight-at-length (95\% CI's) across quantiles 0.1-0.9 for specified length classes of female northern pike from the Thousand Islands region of the St. Lawrence River. Weight-at-length is displayed for three ecologically distinct time periods. Northern pike weight-length models were based on a sample of 2623 fish collected during 1982-2013.

Fig.10. Time period analysis - Parameter estimates (95\% CI's) for quantile regression weightlength ( $\log _{10}$-transformed) models for smallmouth bass collected in the Thousand Islands Region of the St. Lawrence River (1982-2013). Variables included in the final models were selected using Bayesian information criterion. Candidate models included terms for $\log _{10}$ length (TL), time period, sex, and one-way interactions. Time period $1=1982$ 1992; time period $2=1993-2004$; time period $3=2005-2013$. 
720

721

722

723

724

725

726

727

728

729

730

731

732

733

734

735

736

737

738

Fig. 11. Time period analysis - Parameter estimates (95\% CI's) for quantile regression weightlength ( $\log 10$-transformed) models for northern pike collected in the Thousand Islands Region of the St. Lawrence River (1982-2013). Variables included in the final models were selected using Bayesian information criterion. Candidate models included terms for $\log 10$ length (TL), time period, sex, and one-way interactions. Time period $1=1982-$ 1992; time period $2=1993-2004$; time period $3=2005-2013$.

Fig. 12. Biological and environmental variable analysis - Parameter estimates (95\% CI's) for quantile regression weight-length ( $\log _{10}$-transformed) models for smallmouth bass collected in the Thousand Islands Region of the St. Lawrence River (1982-2013). Variables included in the final models were selected using Bayesian information criterion. Candidate models included terms for $\log _{10}$ total length (TL), presence of round goby $(\mathrm{RG})$, presence of dreissenid mussels (DM), mean summer water temperature (temp), abundance of conspecifics (CPU), and one way interactions between variables.

Fig. 13. Changes in median weight-at-length (\%) of smallmouth bass following invasion of dreissenid mussels in the Thousand Islands region of the St. Lawrence River. The solid line represents the estimated change in weight-at-length and the dashed lines represent upper and lower $95 \%$ confidence limits. 


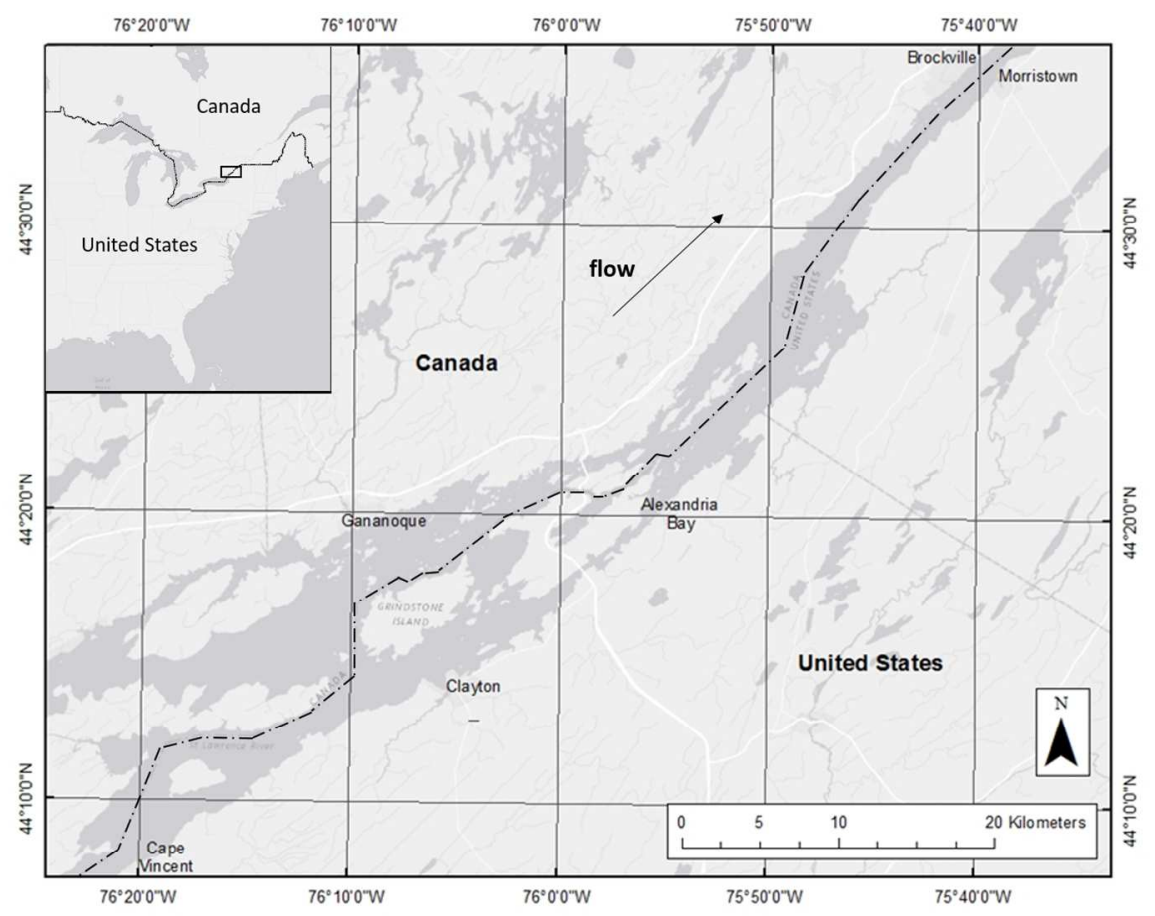

Fig. 1. Map of the Thousand Islands region of the upper St. Lawrence River. Basemap from Esri Inc., 2014. $256 \times 198 \mathrm{~mm}(150 \times 150 \mathrm{DPI})$ 

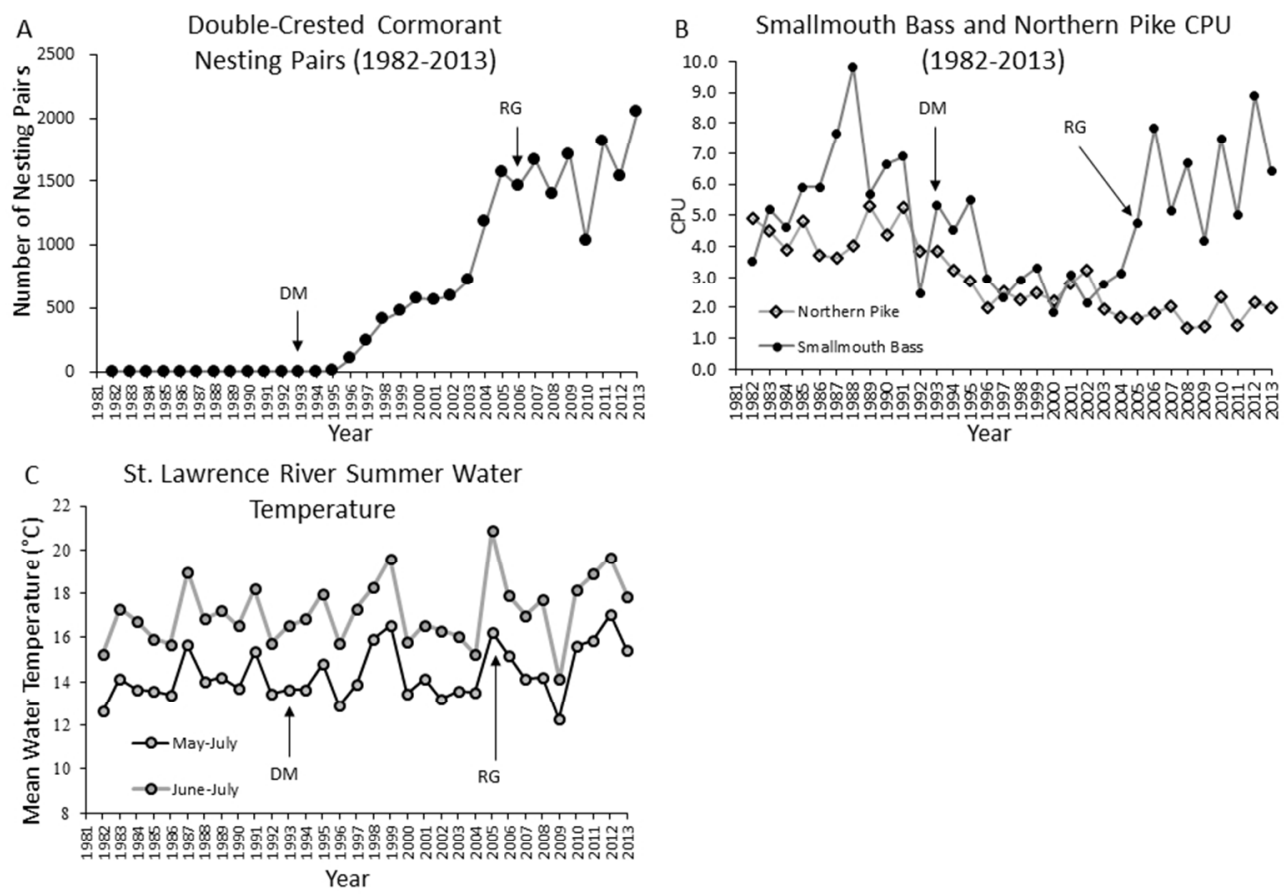

254x190mm (96 x 96 DPI) 


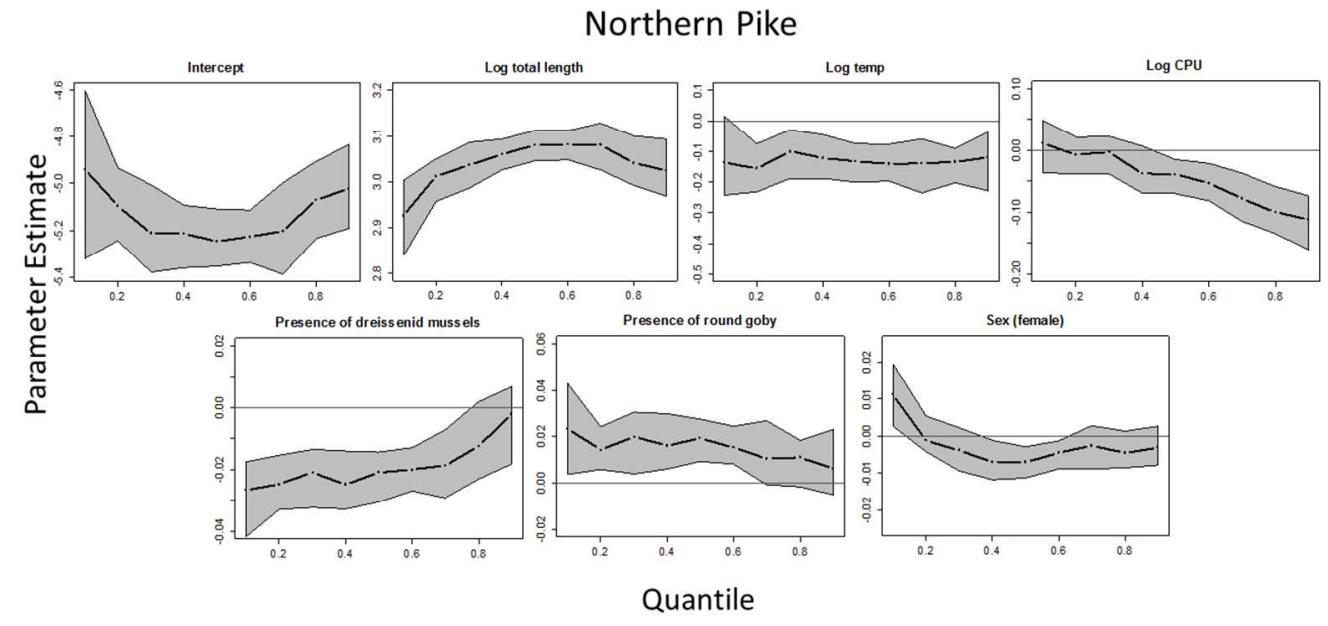

$338 \times 160 \mathrm{~mm}(96 \times 96$ DPI $)$ 

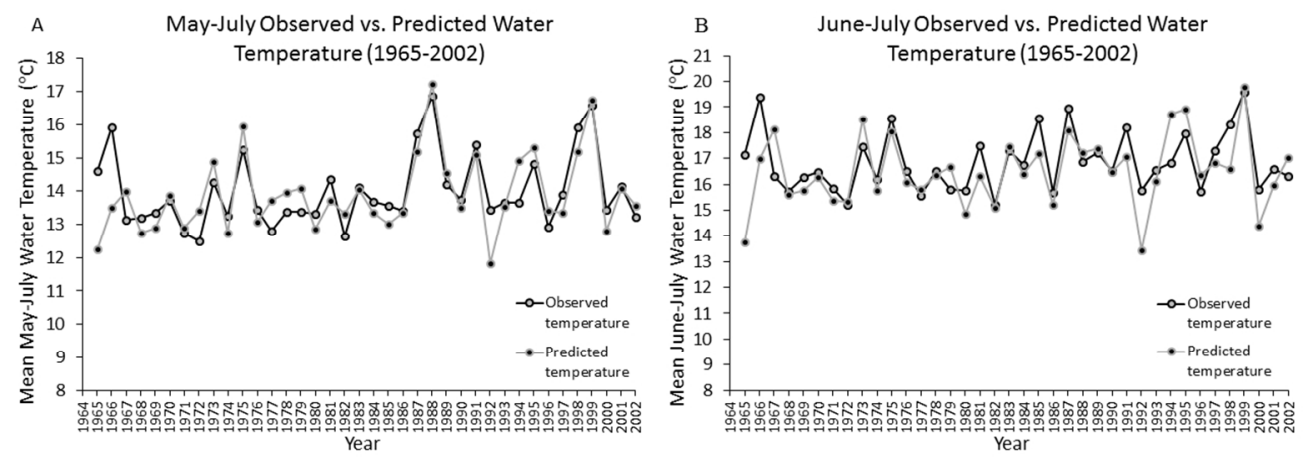

$338 \times 121 \mathrm{~mm}(96 \times 96$ DPI) 


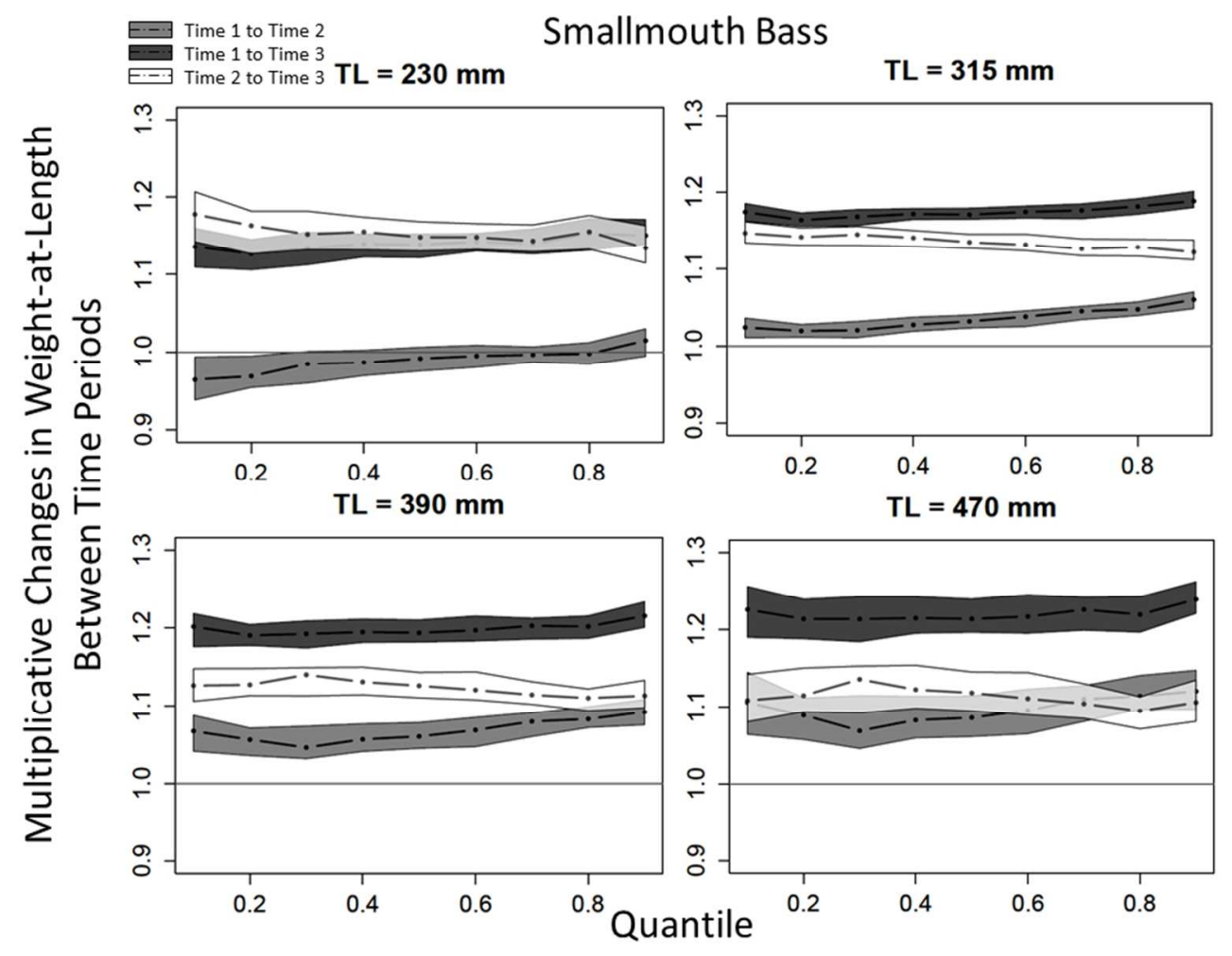

$252 \times 190 m m(96 \times 96$ DPI $)$ 


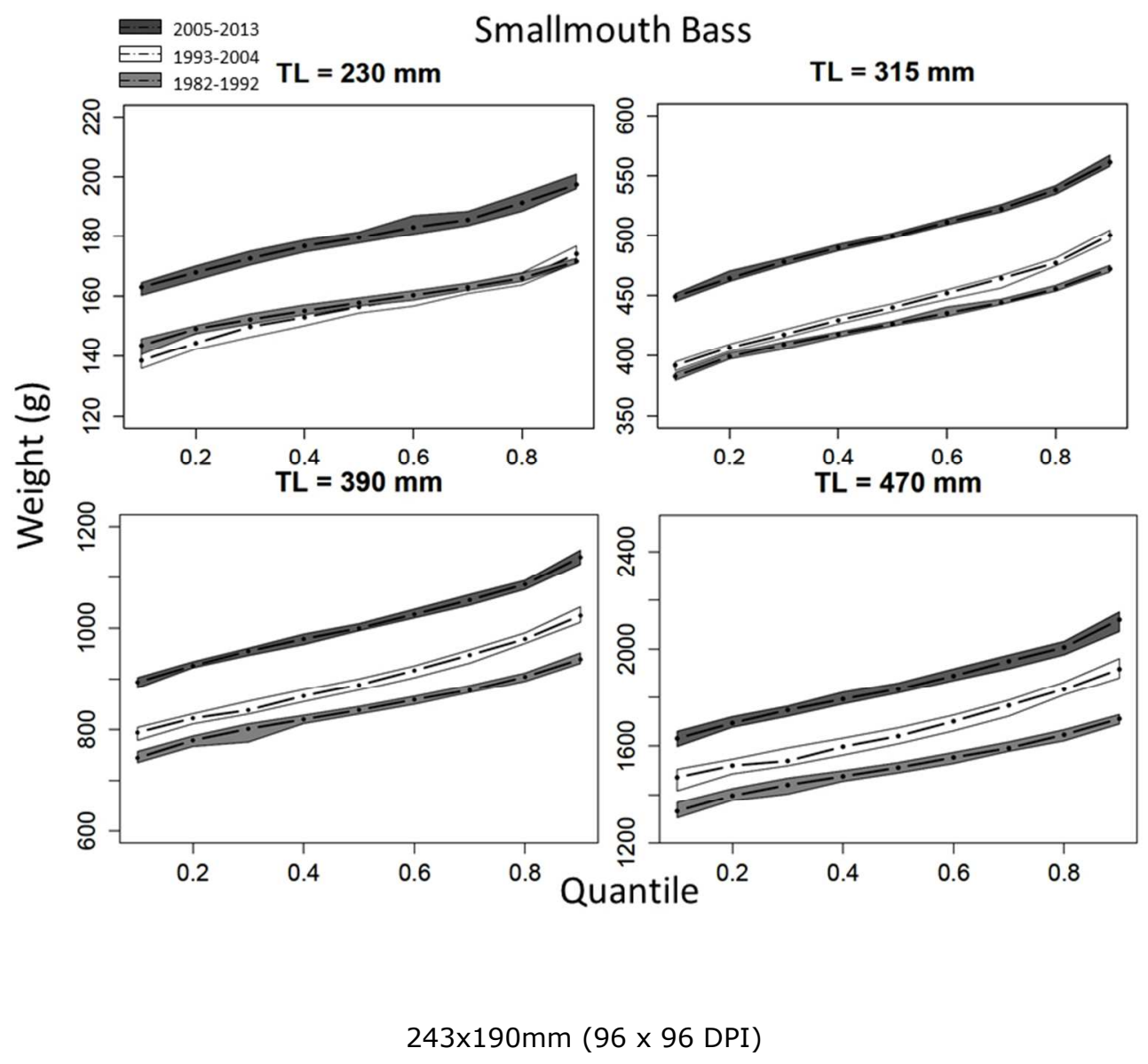




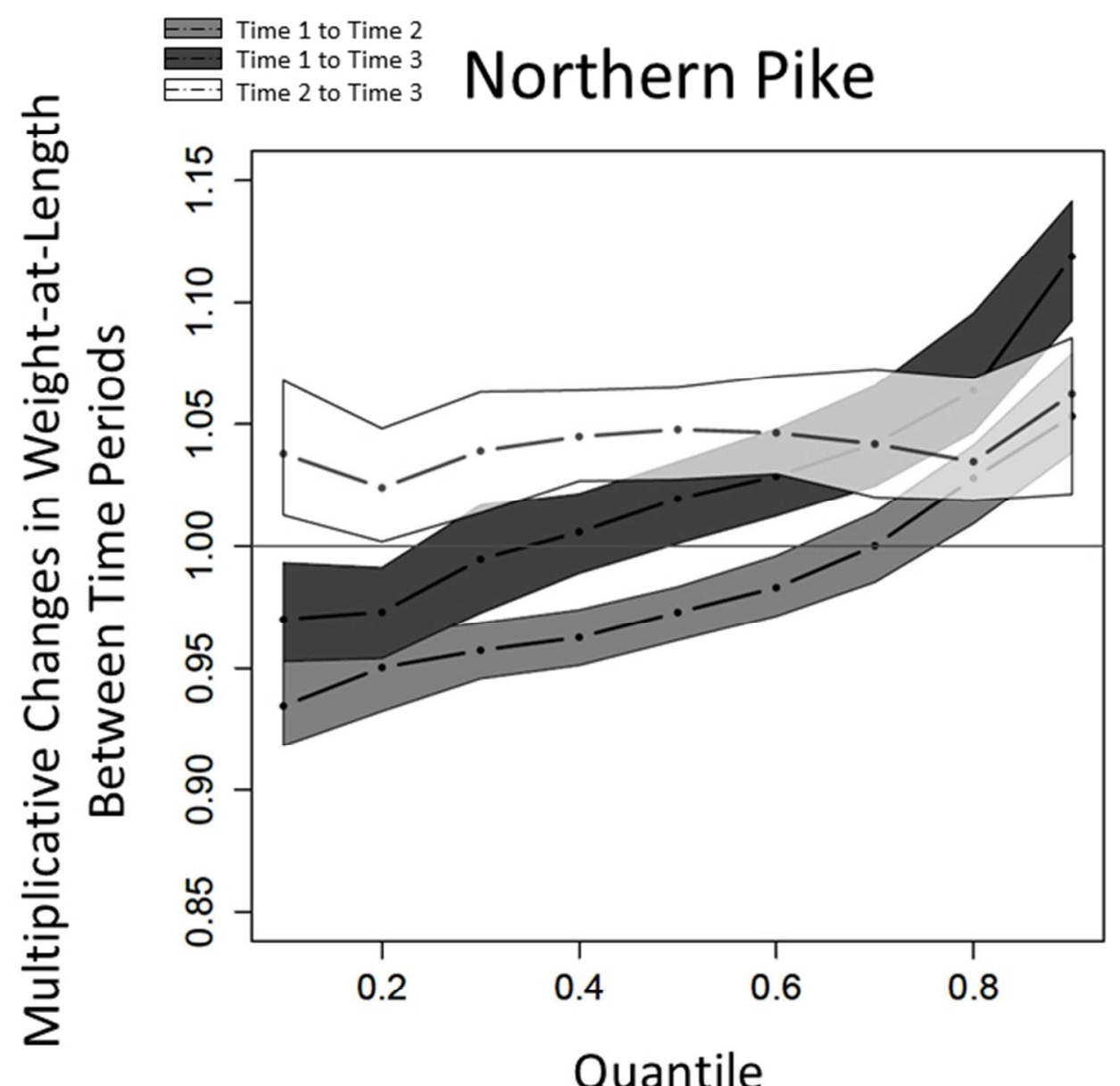

$179 \times 169 \mathrm{~mm}(96 \times 96$ DPI) 


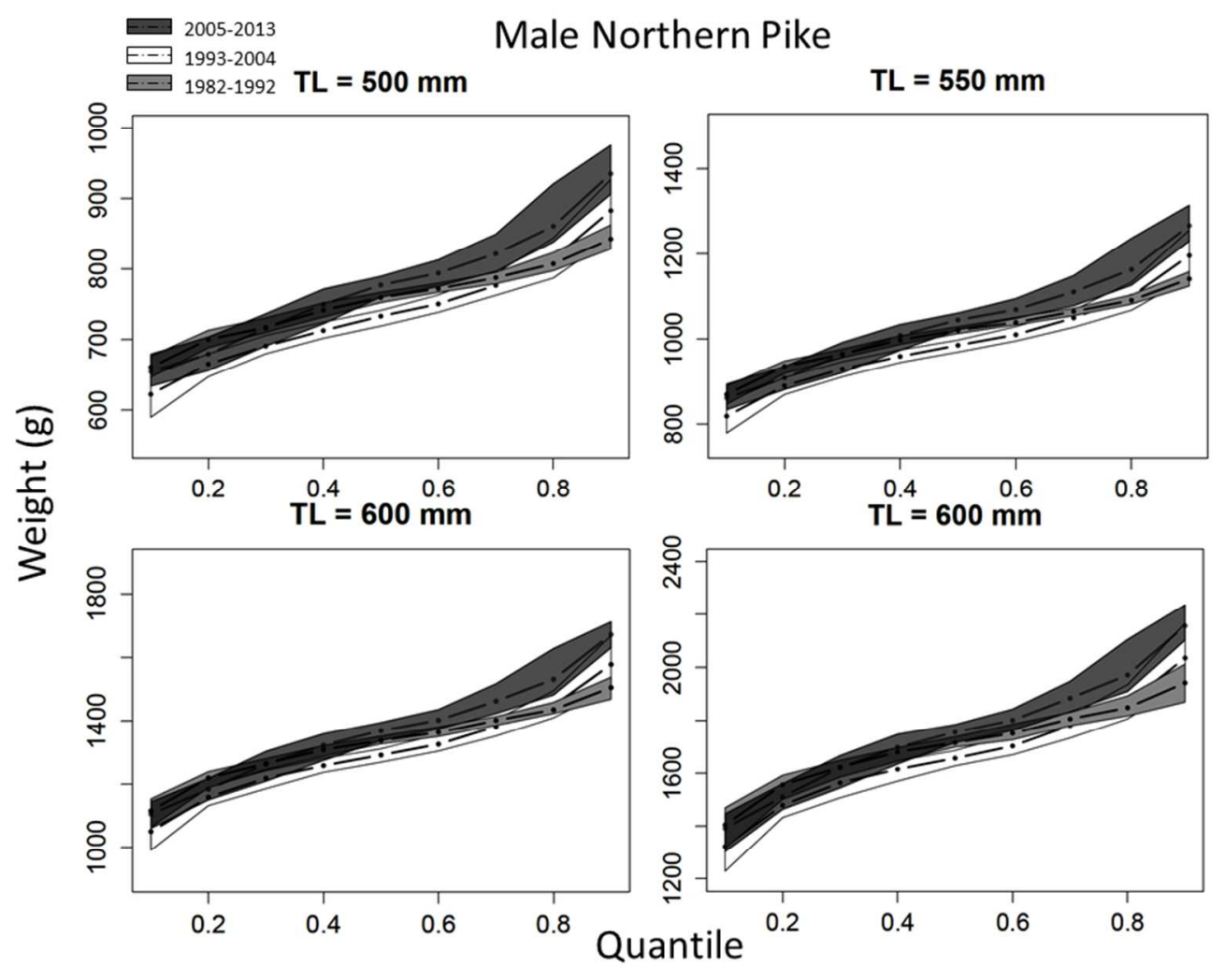

$241 \times 190 \mathrm{~mm}(96 \times 96$ DPI $)$ 


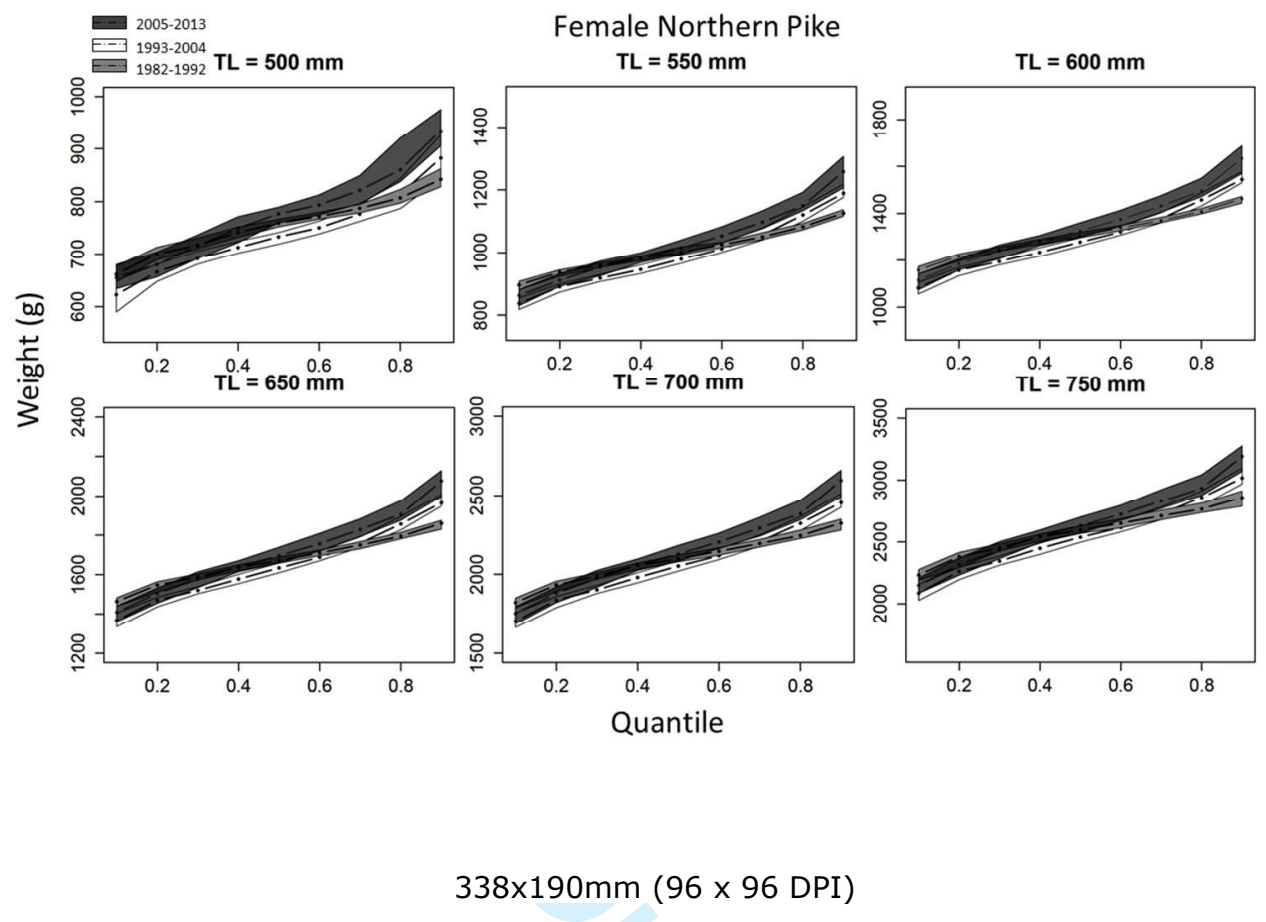

https://mc06.manuscriptcentral.com/cjfas-pubs 

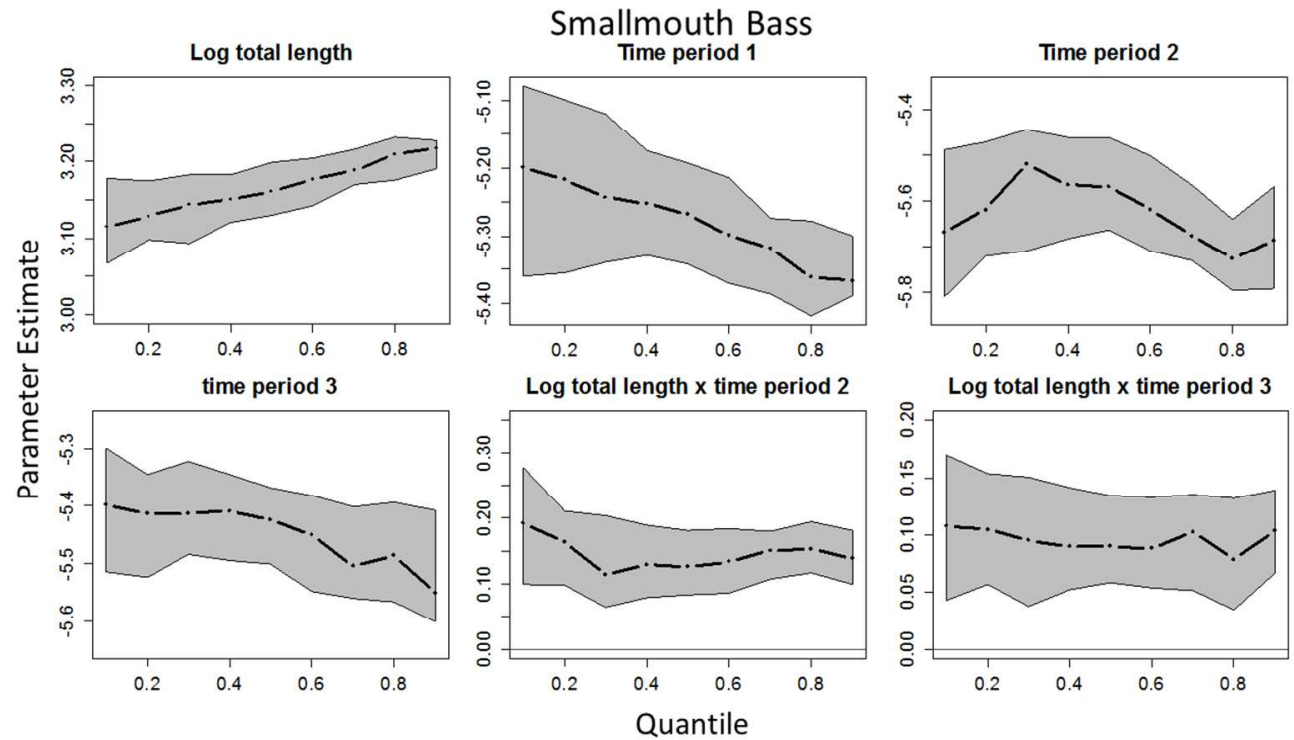

$338 \times 190 \mathrm{~mm}(96 \times 96$ DPI) 


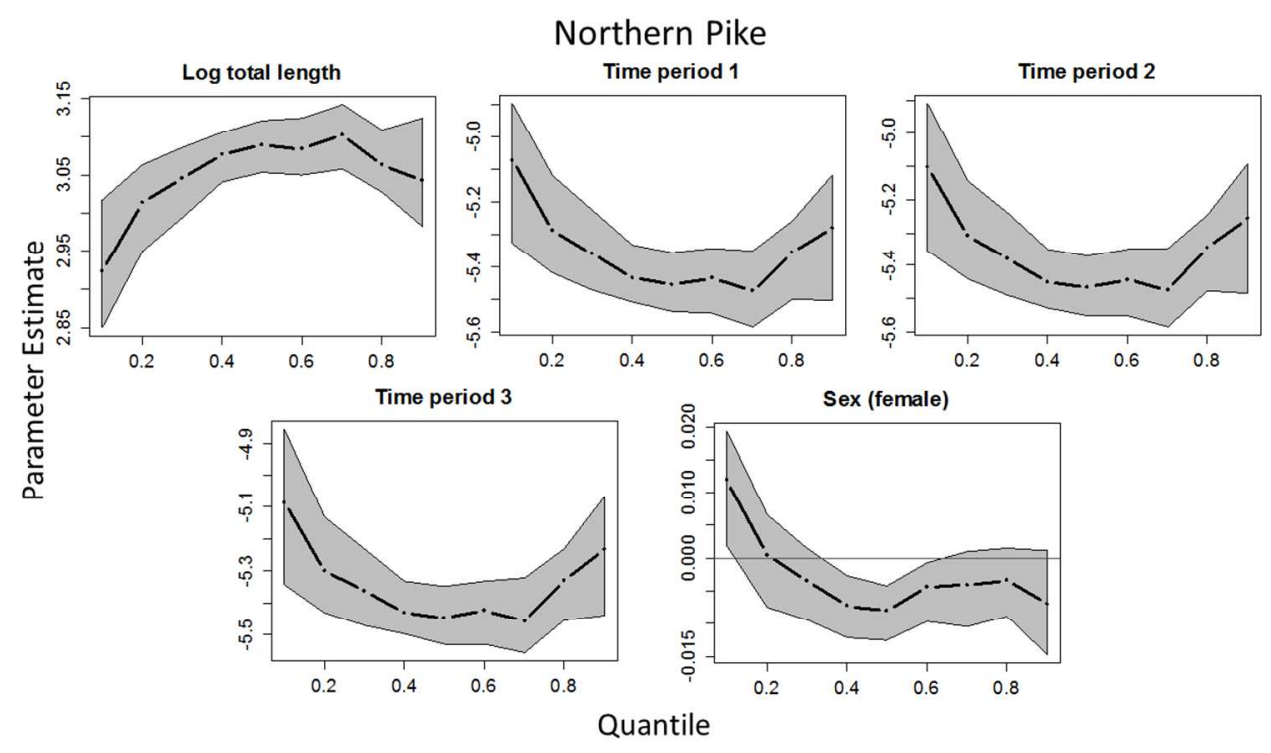

$338 \times 190 \mathrm{~mm}(96 \times 96$ DPI) 


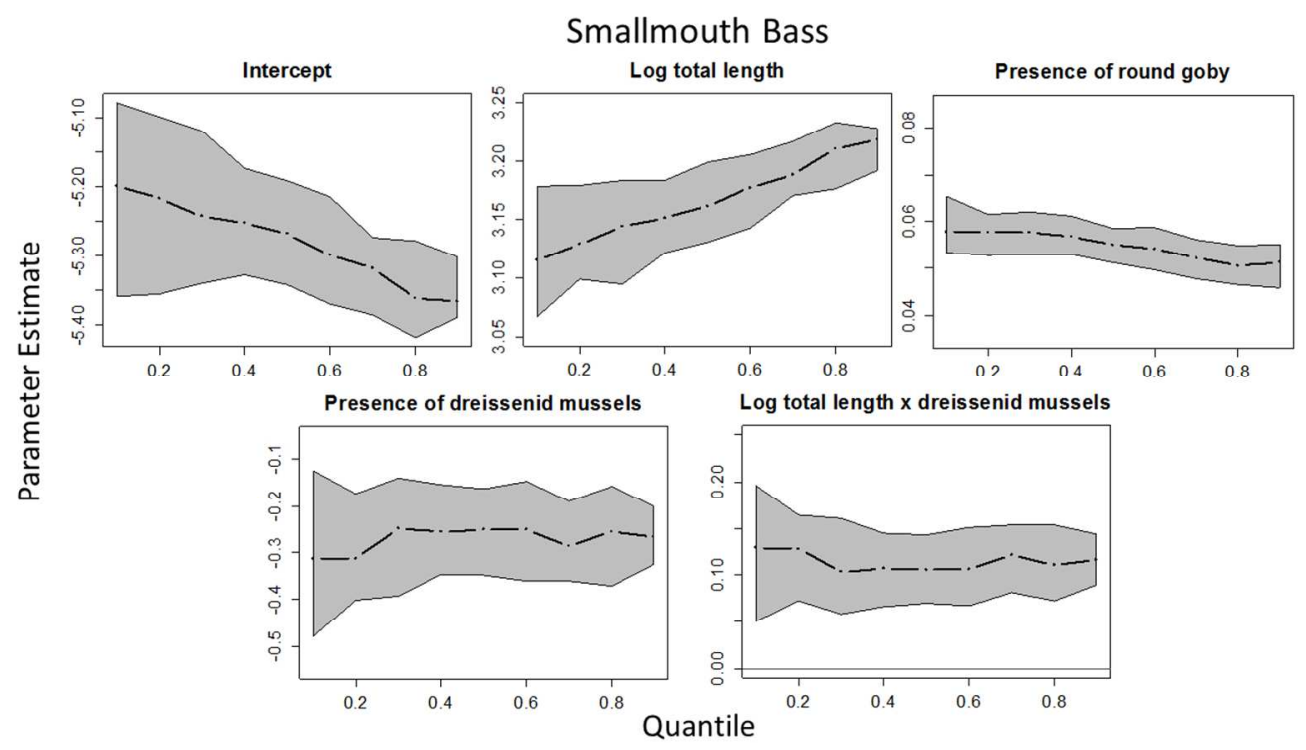

$338 \times 190 \mathrm{~mm}(96 \times 96$ DPI $)$ 


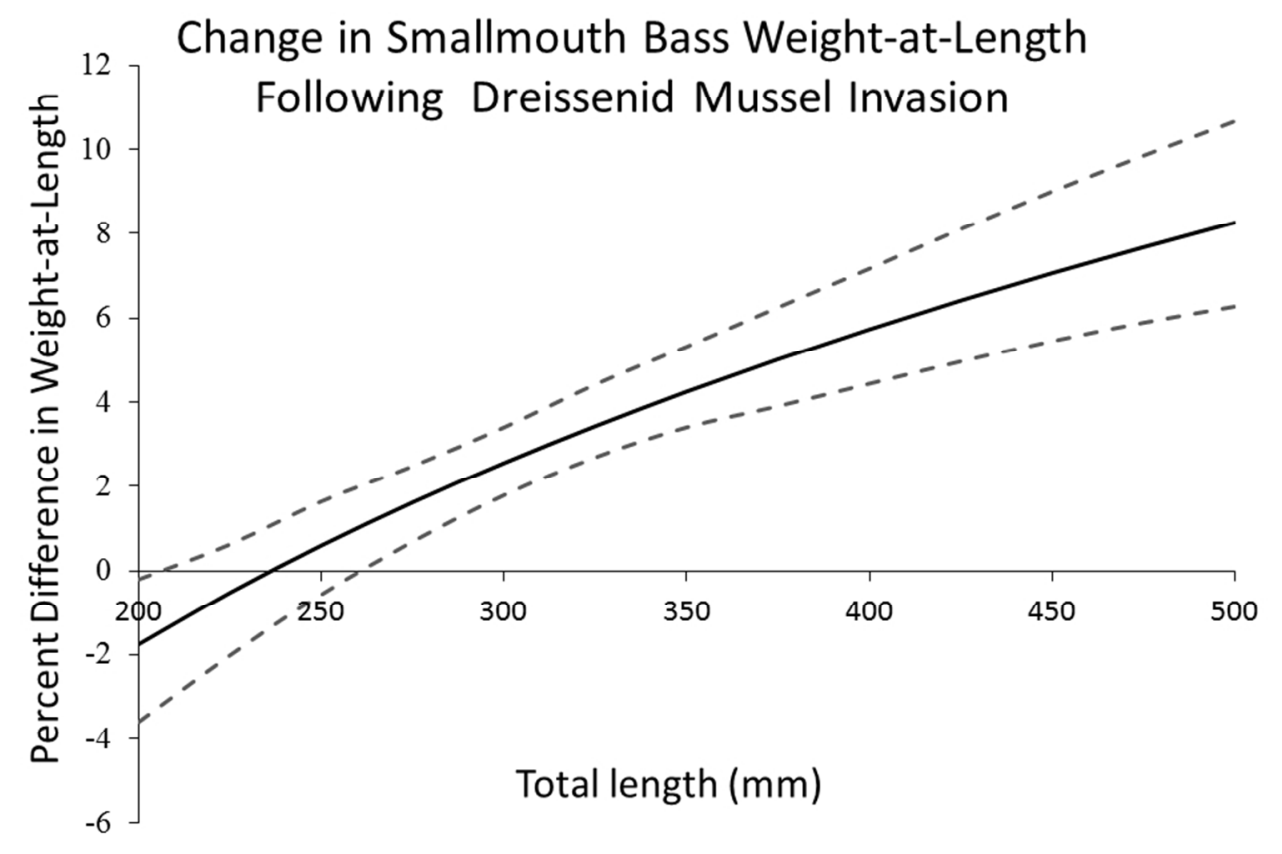

$258 \times 176 \mathrm{~mm}(96 \times 96$ DPI) 